\title{
Effect of pre-strain on work- hardening behavior of magnesium alloy sheets upon cyclic loading
}

\section{$\operatorname{AUTHOR}(S)$ :}

Hama, Takayuki; Nagao, Hirotaka; Kobuki, Akihiro; Kuchinomachi, Yota; Takuda, Hirohiko

\section{CITATION:}

Hama, Takayuki ... [et al]. Effect of pre-strain on work-hardening behavior of magnesium alloy sheets upon cyclic loading. Materials Science and Engineering A 2014, 591: 66-77

\section{ISSUE DATE:}

2014-01-03

URL:

http://hdl.handle.net/2433/237629

\section{RIGHT:}

(c) 2014. This manuscript version is made available under the CC-BY-NC-ND 4.0 license

http://creativecommons.org/licenses/by-nc-nd/4.0/:; The full-text file will be made open to the public on 3 January 2016 in accordance with publisher's 'Terms and Conditions for Self-Archiving'; This is not the published version. Please cite only the published version.; この論文は出版社版でありません。引用の際には出版社版をご確認じ利用ください。 


\section{Effect of Pre-strain on Work-Hardening Behavior of Magnesium}

\section{Alloy Sheets upon Cyclic Loading}

Takayuki HAMA*

Hirotaka NAGAO

Yota KUCHINOMACHI

Hirohiko TAKUDA

Department of Energy Science and Technology, Kyoto University, Yoshida-honmachi,

Sakyo-ku, Kyoto 606-8501, Japan

Corresponding author: Takayuki HAMA

Department of Energy Science and Technology, Kyoto University

Yoshida-Honmachi, Sakyo-ku, Kyoto 606-8501, Japan

TEL: $\quad+81-(0) 75-753-5418$

FAX: $\quad+81-(0) 75-753-5428$

E-mail: hama@energy.kyoto-u.ac.jp 


\section{Abstract}

This paper reports the effect of pre-strain on the work-hardening behavior of rolled AZ31 magnesium alloy sheets during in-plane cyclic loading. The work-hardening behavior of the alloy remained almost unchanged when tensile strain was applied before cyclic loading. However, the work-hardening behavior was significantly affected when a compressive strain was applied. First, the resulting stress-strain curve was not sigmoidal upon tension in some cases, depending on the magnitudes of the applied compressive pre-strain owing to the inversion of the loading direction from tension to compression before the second increase in the work-hardening rate. In other words, a sigmoidal stress-strain curve certainly arose upon tension when compressive pre-strain was applied and the loading direction was not inverted from tension to compression. It was found that the strain at the beginning of the second increase had a high correlation with the volume fraction of twins. Second, the change in the rate of work-hardening at the beginning of tension became sharp as compressive pre-strain increased, probably owing to the effect of activation of detwinning on the stress-strain curve, which became increasingly significant as the compressive pre-strain increased the volume fraction of twins. 
Keywords: magnesium alloy sheet, in-plane cyclic loading, pre-strain, twinning, work-hardening

\section{Introduction}

Mg alloys have attracted a great deal of attention because of an increasing demand for lightweight materials to reduce $\mathrm{CO}_{2}$ emission from transport equipment. In general, Mg alloys used for components are made by die casting and thixoforming. Because press forming of sheet metal is an efficient process to manufacture thin-walled structural components, press forming of Mg alloy sheets has received much attention, and many studies on the press formability of $\mathrm{Mg}$ alloy sheets have been carried out [1-11]. However, the number of structural components manufactured by press forming of $\mathrm{Mg}$ alloy sheets is still small. One of the reasons is that the deformation behavior of $\mathrm{Mg}$ alloy sheets is significantly different from those of conventional metal sheets used for structural components. For instance, rolled $\mathrm{Mg}$ alloy sheets show asymmetric deformation between tension and compression, exhibit nonlinear deformation during unloading, and display strong anisotropic work-hardening behavior through successive changes in the shapes of their yield loci. Such characteristic deformations in Mg alloy 
sheets are the result of magnesium's hexagonal close-packed (HCP) structure, which exhibits significant crystal anisotropy and allows easy activation of direction-dependent \{10-12\} deformation twinning . Therefore, many studies have been carried out to understand the work-hardening behavior as well as the formability of $\mathrm{Mg}$ alloys [12-23].

During press forming, a metal sheet is often subjected to cyclic loading such as cyclic bending-unbending processes. Consequently, the deformation behavior under cyclic loading conditions have been extensively studied in various metals used for structural components, including aluminum alloys and steels [24-27], and in Mg alloys [21, 28-36]. These past studies on Mg alloys focused particularly on their fatigue properties, studied using a very large number of cycles and a relatively small strain amplitude. A literature survey of the past studies on fatigue properties can be found in [21].

During press forming, a metal sheet is subjected to several cycles during which large plastic strains arise accordingly, showing that cyclic-loading conditions necessary for the study of press forming would be different from those used for study of fatigue properties. In our previous study [21], the work-hardening behavior of a rolled Mg alloy sheet was investigated under in-plane cyclic tension-compression conditions with 
relatively high strain amplitudes and small cycle numbers. The effects of twinning and detwinning on the work-hardening behavior were also investigated. In summary, we found that the work-hardening behavior was asymmetrical between tension and compression as follows: the rate of work-hardening in the later stages of compression increased as the number of cycles increased, whereas rate in the later stages of tension decreased. It was also found that the work-hardening behavior could be explained in terms of twinning and detwinning. The work-hardening behavior was also affected by the strain amplitude of cyclic loading.

In our previous study [21], we also showed that the work-hardening behavior remained unchanged when a tensile pre-strain was applied before a cyclic loading test was carried out, while they were significantly affected when a compressive pre-strain was applied. In particular, the sigmoidal shape in the stress-strain curve that generally occurs upon tension following compression did not arise when a pre-strain of $-4 \%$ was applied before the cyclic loading test with a strain amplitude of $6 \%$. These results indicated that the work-hardening behavior might be subjected to significant changes by the loading history of the sample. However, the experiments were carried out only with the conditions of a strain amplitude of $6 \%$ and pre-strains of $4 \%$ and $-4 \%$ in the previous study. Therefore, changes in the work-hardening behavior as a function of the 
pre-strain are not yet understood. Particularly, changes in the stress-strain curve during inversion of loading from compression to tension in one cycle depending on the pre-strain and the strain amplitude are not clear, which hinders an accurate prediction of the work-hardening behavior.

In the present paper, the effect of pre-strain on the work-hardening behavior under in-plane cyclic tension-compression was investigated. We focused our attention on the effect of pre-strain on the work-hardening behavior upon tension following compression. Cyclic loading tests were carried out with strain amplitudes of $2 \%, 4 \%$, and $6 \%$ after pre-strains of $4 \%, 0 \%,-2 \%,-4 \%,-5 \%$, and $-6 \%$ were applied. Metallographic observations using an optical microscope were also used to examine the correlation between the twinning activity and the work-hardening behavior.

2. Experimental procedures

\subsection{Material}

In the present study, commercial rolled AZ31B Mg alloy sheets ( $\mathrm{Mg}-3 \% \mathrm{Al}, 1 \%$ Zn, Osaka Fuji Corporation) of two thicknesses were used, 0.8 and $1 \mathrm{~mm}$. The sheet with a thickness of $0.8 \mathrm{~mm}$ was the same as that used in our previous study [21]. The material with a thickness of $1.0 \mathrm{~mm}$ was used in additional experiments where very 
large compressive pre-strains were applied, which will be explained in detail in section

4. Sheets with thicknesses of 0.8 and $1.0 \mathrm{~mm}$ are referred to as A and B, respectively.

The mechanical properties of the sheets obtained from uniaxial tension tests are shown

in Table 1. A sample preparation procedure of specimen was the same as in our

previous study [21]. The geometry of the specimen used is shown in Fig. 1. The specimens were machined parallel to the rolling direction, and were annealed at $350{ }^{\circ} \mathrm{C}$ for $1.5 \mathrm{~h}$ before conducting the experiments.

2.2. Experimental procedure of in-plane cyclic loading test

The experimental procedure for the in-plane cyclic loading test was the same as that used in our previous study [21], and has been explained briefly as follows. Comb-shaped dies were used to suppress buckling during compression [37]. A photograph of the experimental setup is shown in Fig. 2. The compressive forces in the thickness direction were applied through the elastic forces of four coil springs. The magnitude of the compressive force was $5 \mathrm{kN}$, which was much smaller than the $0.2 \%$ proof stresses of the sheets. Mineral hydraulic oil with a nominal kinetic viscosity of 32 cSt at $40{ }^{\circ} \mathrm{C}$ was used as a lubricant.

The experiment was carried out at an initial strain rate of $6.67 \times 10^{-4} \mathrm{~s}^{-1}$ at room 
temperature. A strain gauge was used to measure strains in the loading direction during the test. The cyclic loading test was carried out with strain amplitudes of $2 \%, 4 \%$ and $6 \%$ after pre-strains of $4 \%, 0 \%,-2 \%,-4 \%,-5 \%$ and $-6 \%$ were applied. The definitions of the strain amplitude $\varepsilon_{S}$ and the pre-strain $\varepsilon_{\mathrm{P}}$ are described in Fig. 3 where a stress-strain curve with a strain amplitude of $6 \%$ and a pre-strain of $-2 \%$ is shown. Because of the capacity limitation of the experimental setup, the maximum pre-strain that could be given under a strain amplitude of $6 \%$ was $-5 \%$. It should also be noted that the cyclic loading tests with pre-strains of $4 \%$ and $0 \%$ were started with tension, while those with pre-strains of $-2 \%,-4 \%$ and $-6 \%$ started with compression. The case with a pre-strain of $0 \%$ is henceforth termed as the original case.

To examine the activity of twinning during cyclic loading, microstructures were observed using an optical microscope. A sample was chemically etched by a mixture of $1.05 \mathrm{~g}$ picric acid, $16.45 \mathrm{~mL}$ ethanol, $2.5 \mathrm{~mL}$ acetic acid, and $2.5 \mathrm{~mL}$ distillated water. The area fraction of twins measured by image analysis was used to evaluate the activity of twinning. The area fraction of twins, $R_{\text {twin }}$, is given by the equation:

$$
R_{t w i n}=\frac{S_{t w i n}}{S} \times 100
$$

where $S_{\text {twin }}$ is the area of the twins that were present in the observed microstructures, and $S$ is the entire area of the observed microstructures. For further details on the 
experimental procedure, the reader is requested to refer to literature [21].

\section{Experimental results}

In our previous study [21], the results of the cyclic loading with a strain amplitude of $6 \%$ were mainly used to examine the work-hardening behavior. Therefore, the effect of the pre-strain on the work-hardening behavior during the cyclic loading with a strain amplitude of $6 \%$ was examined first. Fig. 4 shows the stress-strain curves of material A (0.8 mm thick) obtained with a strain amplitude of $6 \%$ and pre-strains of $4 \%, 0 \%,-2 \%$, $-4 \%$, and $-5 \%$. Figs. 4 (a), (b), and (d) are reprinted from the literature [21] with permission. Fig. 5 shows the result of material B obtained with a strain amplitude of $6 \%$ and a pre-strain of $-4 \%$ for comparison. Fig. 6 shows the relationship between the number of cycles and the stresses at the end of tension and compression obtained from Figs. 4 and 5.

First, the results of the two Mg alloy sheets were compared (Figs. 4 (d) and 5). Clearly, the two Mg alloy sheets showed very similar stress-strain curves. Furthermore, the variations of the stress at the end of tension and compression were almost identical (Fig. 6), indicating that the two sheets exhibited almost identical deformation behavior, although they had different thicknesses. In the remainder of this section, the results of 
material A are used to explain the work-hardening behavior.

As explained in the literature [21], the tendencies observed in the original result (pre-strain of 0\%, Fig. 4 (b)) can be summarized as follows. A sigmoidal shape, which consists of the first increase in the rate of work-hardening, the plateau region, and the second increase in the rate of work-hardening, was found during tension. The rate of work-hardening in the later stage of compression gradually increased as the number of cycles increased, whereas that in the late stage of tension decreased as the number of cycles increased. Thus, the stress-strain curve was asymmetrical between the tension and the compression. In the present paper, the first and second increases in the rate of work-hardening during tension are termed the first and second stages of work-hardening, respectively.

Next, the effect of pre-strain on the results with a strain amplitude of $6 \%$ was examined. When the tensile pre-strain was applied (Fig. 4 (a)), the tendencies observed in the stress-strain curve remained unchanged from the original result (Fig. 4 (b)) as explained in our previous study. On the other hand, tendencies were different when compressive pre-strains were applied (Figs. 4 (c), (d), and (e)). In the late stage of compression, the increase in the rate of work-hardening with the number of cycles became large as the compressive pre-strain increased. As a result, the rate of increase in 
stress as well as the magnitudes of stress at the end of compression became large as the compressive pre-strain increased (Fig. 6 (a)).

A change in the tendency in the late stage of tension was more significant. When pre-strains of $-4 \%$ and $-5 \%$ were applied, the second stage of work-hardening did not occur; thus, the decrease in the rate of work-hardening with the number of cycles that was observed in the original result (Fig. 4 (b)) did not arise. On the other hand, when a pre-strain of -2\% was applied, the tendency was almost the same as that of the original result. As a result of the differences in the tendency depending on the pre-strain, the stress at the end of tension gradually increased with the number of cycles when pre-strains of $-4 \%$ and $-5 \%$ were applied, whereas this decreased when a pre-strain of -2\% was applied (Fig. 6 (b)).

Next, the effect of strain amplitude on the work-hardening behavior was investigated. The stress-strain curves with strain amplitudes of $2 \%$ and $4 \%$ are shown in Figs. 7 and 8, respectively. Figs. 9 and 10 show the relationships between the number of cycles and the stresses at the end of tension and compression obtained from Figs. 7 and 8 , respectively. The changes with the number of cycles in the rate of work-hardening in the late stages of tension and compression became small as the strain amplitude became small; thus, the changes in stress at the end of tension and compression also became 
gradual (Figs. 9 and 10). That the occurrence of the second stage of work-hardening was different from that with a strain amplitude of $6 \%$ was noted for further discussion. In the results with strain amplitudes of $2 \%$ and $4 \%$, the second stage of work-hardening arose when pre-strains of $0 \%$ and $4 \%$ were applied and did not arise when pre-strains of $-2 \%$, $-4 \%,-5 \%$, and $-6 \%$ were applied. As a result, the stress at the end of tension gradually increased with the number of cycles when pre-strains of $-2 \%,-4 \%,-5 \%$, and $-6 \%$ were applied, whereas this decreased when pre-strains of $0 \%$ and $4 \%$ were applied (Figs. 9 and 10).

\section{Discussion}

4.1 Second stage of work-hardening during tension

The effect of pre-strain on the stress-strain curve during tension is discussed in the following. To investigate the stress-strain curve quantitatively, the curvature at the end of first stage of work-hardening, $\rho_{\mathrm{T}}$, the amount of strain from the beginning of tension to the beginning of the second stage of work-hardening, $\varepsilon_{\mathrm{T}}$, and the gradient during the second stage of work-hardening, $g_{\mathrm{T}}$, are defined. The schematics of these parameters are shown in Fig. 3. $g_{\mathrm{T}}$ was defined by linearly approximating the second stage of work-hardening using the least square method to an accuracy of $99.5 \%$. $\varepsilon_{\mathrm{T}}$ was defined to be the strain from the beginning of tension to the beginning of the linear 
approximation of second stage of work-hardening. $\rho_{\mathrm{T}}$ was defined as follows. The variation of curvature was first calculated from the stress-strain curve using a three-point curvature approximation. $\rho_{\mathrm{T}}$ was defined to be an average of the curvature over the corresponding region (a region where the curvature is relatively uniform).

In this section, the occurrence of second stage of work-hardening is examined in detail. As described in the previous section, the second stage of work-hardening did not arise in some cases depending on the magnitudes of compressive pre-strain and strain amplitude. This might have been because the loading direction was inverted from tension to compression before the second stage of work-hardening arose. If this presumption is correct, the second stage of work-hardening certainly should have occurred when the loading direction was not inverted to compression.

To examine this, a reverse loading test in which certain compressive strains were applied followed by tension to fracture was carried out. In the following, the magnitude of strain at the end of compression is termed $\varepsilon_{\min }$ (Fig. 3). The results are shown in Fig. 11. Because compressive strains larger than $-10 \%$ were applied in the reverse loading test, material B (1.0 mm thick) was used to suppress buckling. It is assumed that the tendency observed in Fig. 11 can also be attained in material A because the deformation behavior of material B was in close agreement with that of material A (Figs. 4 and 5) as 
explained in the previous section.

Clearly, the second stage of work-hardening arose regardless of $\varepsilon_{\min }$. The points a, b, and c shown in Fig. 11 indicate the strains at which the loading direction was inverted to compression in the cyclic loading tests with a strain amplitude of $4 \%$ and pre-strains of $-2 \%,-4 \%$, and $-6 \%$, respectively. The point $d$ in Fig. 11 corresponds to the result with a strain amplitude of $6 \%$ and a pre-strain of $-2 \%$. The second stage of work-hardening had not yet arisen at points a, b, and c, whereas it had already begun at point d. These tendencies are consistent with the results observed in Figs. 8 (c), 8 (d), 8 (f) and 4 (c). These results show that, as we expected, the loading direction was inverted to compression before the second stage of work-hardening began in the cyclic loading tests in which the second stage of work-hardening did not arise.

The above results indicate that the occurrence of second stage of work-hardening during the cyclic loading test was determined by the relationship between the loading conditions, such as the strain amplitude $\varepsilon_{\mathrm{S}}$ and the pre-strain $\varepsilon_{\mathrm{P}}$, and the magnitude of $\varepsilon_{\mathrm{T}}$ (Fig. 3). As shown in Fig. 11, the second stage of work-hardening began after the nominal strain became positive when $\varepsilon_{\min }$ was small, indicating that the magnitude of $\varepsilon_{\mathrm{T}}$ was almost as large as the absolute of $\varepsilon_{\min }$. On the other hand, when $\varepsilon_{\min }$ was large, the second stage of work-hardening began before the nominal strain became positive, 
showing that the magnitude of $\varepsilon_{\mathrm{T}}$ appeared to be smaller than the absolute of $\varepsilon_{\min }$. To examine this tendency in detail, the relationship between $\varepsilon_{\text {min }}$ and $\varepsilon_{\mathrm{T}}$, as shown in Fig. 12 and was obtained from Fig. 11, was used. $\varepsilon_{\mathrm{T}}$ increased almost linearly until $\varepsilon_{\min }$ increased to $-8 \%$, but thereafter, the slope became smaller at higher strains. Clearly, the tendency was different between the small and large strains.

It is generally understood that the deformation until the second stage of work-hardening began is primarily governed by the activation of detwinning, which was determined by the number of twins activated by the end of compression [12, 22, 31]. Therefore, it was presumed that $\varepsilon_{\mathrm{T}}$ had a correlation with the number of twins that were activated by the end of compression. Fig. 13 shows the relationship between $\varepsilon_{\text {min }}$ and the area fraction of twins, and Fig. 14 shows the relationship between the area fraction of twins and $\varepsilon_{\mathrm{T}}$. As we expected, the tendency observed in Fig. 13 is similar to that observed in Fig. 12, and furthermore, $\varepsilon_{\mathrm{T}}$ clearly had a strong correlation with the area fraction of twins. From this result, it is expected that $\varepsilon_{\mathrm{T}}$ may be modeled as a function of the area fraction of twins.

We further found that such a correlation is seen not only in $\varepsilon_{\mathrm{T}}$ but also in other properties of the work-hardening behavior during tension. Fig. 15 shows the relationship between the area fraction of twins and the gradient during the second stage 
of work-hardening $g_{\mathrm{T}}$ (Fig. 3). $g_{\mathrm{T}}$ also had a strong correlation with the area fraction of twins. It is generally understood that the activities of slip systems are dominant during the second stage of work-hardening, i.e., the effects of twinning and detwinning on the second stage of work-hardening are small [12, 22, 31]. However, Fig. 15 clearly shows that the activities of twinning and/or detwinning affected the deformation during the second stage of work-hardening. The mechanism of this twinning and detwinning effect will be investigated in our future work.

4.2 First stage of work-hardening during tension

The change in the rate of work-hardening at the end of first stage of work-hardening is discussed in this section. $\rho_{\mathrm{T}}$ (Fig. 3) was calculated for the first cycle of the stress-strain curves in Figs. 4, 7, and 8, and the correlation between $\varepsilon_{\min }$ and $\rho_{\mathrm{T}}$ is shown in Fig. 16. $\rho_{\mathrm{T}}$ was small when $\varepsilon_{\text {min }}$ was small and became large as $\varepsilon_{\text {min }}$ increased, indicating that the change in the rate of work-hardening at the end of the first stage of work-hardening increased as the compressive pre-strain and/or the strain amplitude became large in the cyclic loading. A similar tendency was also observed in the reverse loading tests (Fig. 11).

The mechanism of this deformation behavior can be explained in terms of the 
change in crystallographic orientations as follows. It is established that a stress-strain curve shows a sudden change in gradient at the yield point when a rolled Mg alloy sheet is subjected to in-plane compression. This may be because the twinning activation begins simultaneously in a large number of grains owing to the strong basal texture [18]. A similar explanation may be applicable to the end of first stage of work-hardening during tension. As explained in the previous section, the deformation until the second stage of work-hardening began was primarily governed by the activity of detwinning. When the compressive pre-strain as small, the effect of the activation of detwinning on the stress-strain curve may have been small because the area fraction of twins was still small (Fig. 13); thus, the stress-strain curve at the end of first stage of work-hardening was gradual. On the other hand, the area fraction of twins became large as the compressive pre-strain increased (Fig. 13). Hence, the effect of the activation of detwinning on the stress-strain curve would also become large, leading to the sharp change at the end of first stage of work-hardening.

If this presumption is correct, a similar tendency may be observed under compression, i.e. the curvature at the yield point under compression also becomes small as the intensity of basal texture becomes weak. To examine this presumption, the curvature at the yield point under compression ( $\rho_{\mathrm{C}}$ in Fig. 3) was calculated for the 
second cycle of the stress-strain curves in Figs. 4, 7, and 8. $\rho_{\mathrm{C}}$ was calculated in the same manner as that of $\rho_{\mathrm{T}}$. Fig. 17 shows the relationship between the strain at the beginning of compression and $\rho_{\mathrm{C}}$. As we expected, $\rho_{\mathrm{C}}$ tended to become small as the strain at the beginning of compression became large. This may be because the intensity of texture became weak as the compressive strain increased, verifying the presumption. At the same time, the change in $\rho_{\mathrm{C}}$ was more pronounced as the strain amplitude $\varepsilon_{\mathrm{S}}$ became large. This result indicates that other factors, such as a loading history or the amount of plastic strain, would also affect the curvature. A detailed investigation on other factors will be the subject of our future work.

\section{Conclusions}

In the present paper, the effect of pre-strain on the work-hardening behavior of AZ31 magnesium alloy sheets under conditions of in-plane cyclic tension-compression was investigated experimentally. Metallographic observations too were used to examine the relationship between twinning and the work-hardening behavior. The results obtained in the present study are as follows.

1. The work-hardening behavior upon cyclic loading changed significantly when 
compressive pre-strain was applied. The changes in work-hardening behavior were more pronounced as the compressive pre-strain increased. On the other hand, the work-hardening behavior was almost independent of tensile pre-strain.

2. The occurrence of a sigmoidal stress-strain curve during tension was dependent on only compressive pre-strain and strain amplitude of cyclic loading. For instance, the second increase in the work-hardening rate upon cyclic loading occurred when the compressive pre-strain was small, but the second increase did not occur when the compressive pre-strain was large. The second increase in the work-hardening rate occurred certainly when the loading direction did not invert to compression. This explains why a sigmoidal curve did not occur in the few cases where the loading direction was inverted to compression before the second increase in the work-hardening rate began. The strain at the beginning of the second increase had a strong correlation with the area fraction of twins; thus, the occurrence of the sigmoidal curve may be determined by the activity of twinning.

3. The change in the rate of work-hardening at the end of the first increase of work-hardening increased as the compressive pre-strain increased. The mechanism of 
this behavior was explained in terms of the change in crystallographic orientations as follows. The deformation until the second increase of work-hardening began was primarily governed by the activity of detwinning. The area fraction of twins was still small when the compressive pre-strain was small. As a result, the effect of the detwinning activation on the stress-strain curve may also have been small; thus, the gradient of the stress-strain curve did not change rapidly at the end of the first increase of work-hardening. On the other hand, the area fraction of twins became large as the compressive pre-strain increased. Hence, the effect of detwinning activation on the stress-strain curve would also become large, leading to a sharp change in the rate of work-hardening at the end of first increase of work-hardening.

\section{Acknowledgements}

This work was partially supported by KAKENHI (23760697: Grant-in-Aid for Young Scientist (B)) in Japan.

References

[1] H.J. Kim, S.C. Choi, K.T. Lee, H.Y. Kim, Materials Transactions 49 (2008), 1112-1119. 
[2] J. Kaneko, M. Sugamata, Journal of Japan Institute of Light Metals 54 (2004), 484-492 (in Japanese).

[3] Y.S. Lee, M.C. Kim, S.W. Kim, Y.N. Kwon, S.W. Choi, J.H. Lee, Journal of Materials Processing Technology 187-188 (2007), 103-107.

[4] E. Doege, K. Droder, Journal of Materials Processing Technology 115 (2001), 14-19.

[5] F.K. Chen, T.B. Huang, C.K. Chang, International Journal of Machine Tools \& Manufacture 43 (2003), 1553-1559.

[6] M.H. Lee, H.Y. Kim, H.K. Kim, G.D. Kim, S.I. Oh, Materials Transactions, 49 (2008), 1120-1123.

[7] S. Yi, J. Bohlen, F. Heinemann, D. Letzig, Acta Materialia, 58 (2010), 592-605.

[8] L. Zhang, G. Huang, H. Zhang, B. Song, Journal of Materials Processing Technology, 211 (2011), 644-649.

[9] S.M. Lee, C.G. Kang, S.B. Kang, International Journal of Advanced Manufacturing Technology, 51 (2010), 891-903.

[10] T. Hama, Y. Kariyazaki, K. Ochi, H. Fujimoto, H. Takuda, Materials Transactions 51 (2010), 685-693.

[11] X. Huang, K. Suzuki, Y. Chino, M. Mabuchi, Materials Science and Engineering A 
565 (2013), 359-372.

[12] X.Y. Lou, M. Li, R.K. Boger, S.R. Agnew, R.H. Wagoner, International Journal of Plasticity 23 (2007), 44-86.

[13] T. Hama, K. Ochi, N. Kitamura, H. Fujimoto, H. Takuda, Steel Research International, Special Edition (2011), 1054-1059.

[14] T. Hama, H. Takuda, International Journal of Plasticity, 27(2011), 1072-1092.

[15] C.H. Cáceres, T. Sumitomo, M. Veidt, Acta Materialia 51 (2003), 6211-6218.

[16] G.E. Mann, T. Sumitomo, C.H. Cáceres, J.R. Griffiths, Materials Science and Engineering A 456 (2007), 138-146.

[17] Y. Li M. Enoki, Materials Transactions 49 (2008), 1800-1805.

[18] O. Muránsky, D.G. Carr, P. Sittner, E.C. Oliver, International Journal of Plasticity 25 (2009), 1107-1127.

[19] M. Andar, D. Steglich, T. Kuwabara, in: F. Chinesta, Y. Chastel, M. Mansori (Eds.), International Conference on Advances in Materials and Processing Technologies, American Institute of Physics, 2010, pp. 75-80.

[20] T. Hama, and H. Takuda, Computational Materials Science, 51 (2012), 156-164.

[21] T. Hama, Y. Kariyazaki, N. Hosokawa, H. Fujimoto, H. Takuda, Materials Science and Engineering A, 551 (2012), 209-217. 
[22] T. Hama, and H. Takuda, Steel Research International, Special Edition, (2012), 1115-1118.

[23] T. Hama, N. Kitamura, H. Takuda, Materials Science and Engineering A, 583 (2013), 232-241.

[24] F. Yoshida, T. Uemori, International Journal of Plasticity, 18 (2002), 661-686.

[25] J. Zhang, Y. Jiang, International Journal of Plasticity, 24 (2008), 1890-1915.

[26] O.S. Hopperstad, M. Langseth, S. Remseth, Interantional Journal of Plasticity, 11 (1995), 725-739.

[27] J.L. Chaboche, International Journal of Plasticity, 24 (2008), 1642-1693.

[28] J. Zhang, Q. Yu, Y. Jiang, Q. Li, International Journal of Plasticity 27 (2011), 768-787.

[29] X.Z. Lin, D.L. Chen, Materials Science and Engineering A 496 (2008), 106-113.

[30] S.H. Park, S. Hong, W. Bang, C.S. Lee, Materials Science and Engineering A 527 (2010), 417-423.

[31] L. Wu, S.R. Agnew, T. Ren, D.W. Brown, B. Clausen, G.M. Stoica, H.R. Wenk, P.K. Liaw, AZ31B, Materials Science and Engineering A 527 (2010), 7057-7067.

[32] S.M. Yin, H.J. Yang, S.X. Li, S.D. Wu, F. Yang, Scripta Materialia 58 (2008), 751-754. 
[33] Y. Sunaga, Y. Tanaka, M. Asakawa, M. Katoh, M. Kobayashi, Journal of Japan Institute of Light Metals, 59 (2009), 655-658. (in Japanese)

[34] T. Uota, T. Suzu, S. Fukumoto, A. Yamamoto, Materials Transactions 50 (2009), 2118-2120.

[35] M. Matsuzuki, S. Horibe, Materials Science and Engineering A 504 (2009), 169-174.

[36] C. Guillemer, M. Clavel, G. Cailletaud, International Journal of Plasticity 27 (2011), 2068-2084.

[37] T. Kuwabara, Y. Kumano, J. Ziegelheim, L. Kurosaki, International Journal of Plasticity 25 (2009), 1759-1776. 
Figure and table captions

Table 1. Mechanical properties of sheet materials obtained by a uniaxial tension test. $^{\text {a }}$

Fig. 1. Geometry of a specimen used in the cyclic loading test

Fig. 2. Photograph of the experimental setup for the cyclic loading test.

Fig. 3. Symbol definitions. Stress-strain curve of material A with a strain amplitude of $6 \%$ and a pre-strain of $-2 \%$ is shown.

Fig. 4. Stress-strain curves obtained by cyclic loading tests with a strain amplitude of $6 \%$ and pre-strains of (a) $4 \%$, (b) $0 \%$, (c) $-2 \%$, (d) $-4 \%$, and (e) $-5 \%$. Material A was used. (The results of (a), (b), and (d) are reproduced from the literature with permission [21].)

Fig. 5. Stress-strain curve obtained by cyclic loading test with a strain amplitude of $6 \%$ and a pre-strain of $-4 \%$. Material B was used.

Fig. 6. Changes in stress at the end of tension and compression for the results with a strain amplitude of 6\%: (a) stress at the end of compression and (b) stress at the end of tension.

Fig. 7. Stress-strain curves obtained by cyclic loading tests with a strain amplitude of $2 \%$ and pre-strains of (a) $4 \%$, (b) $0 \%$, (c) $-2 \%$, (d) $-4 \%$, (e) $-5 \%$, and (f) $-6 \%$. 
Material A was used.

Fig. 8. Stress-strain curves obtained by cyclic loading tests with a strain amplitude of $4 \%$ and pre-strains of (a) 4\%, (b) $0 \%$, (c) $-2 \%$, (d) $-4 \%$, (e) $-5 \%$, and (f) $-6 \%$. Material A was used.

Fig. 9. Changes in stress at the end of tension and compression for the results with a strain amplitude of 2\%: (a) stress at the end of compression and (b) stress at the end of tension.

Fig. 10. Changes in stress at the end of tension and compression for the results with a strain amplitude of 4\%: (a) stress at the end of compression and (b) stress at the end of tension.

Fig. 11. Stress-strain curves obtained by reverse loading tests with various $\varepsilon_{\min }$ values.

Fig. 12. Relationship between $\varepsilon_{\min }$ and $\varepsilon_{\mathrm{T}}$.

Fig. 13. Relationship between $\varepsilon_{\min }$ and area fraction of twins.

Fig. 14 Relationship between area fraction of twins and $\varepsilon_{\mathrm{T}}$.

Fig. 15. Relationship between area fraction of twins and $g_{\mathrm{T}}$.

Fig. 16. Relationship between $\varepsilon_{\min }$ and $\rho_{\mathrm{T}}$.

Fig. 17. Relationship between strain at the beginning of compression and $\rho_{\text {C. }}$. 


\begin{tabular}{ccccccccc} 
Material & thickness/mm & E/GPa & $\sigma_{0.2} / \mathrm{MPa}$ & $\sigma_{T} / \mathrm{MPa}$ & $r_{10 \%}$ & $r_{15 \%}$ & $F / \mathrm{MPa}$ & $n$ \\
\hline $\mathrm{A}$ & 0.8 & 40 & 168 & 264 & 2.25 & 2.79 & 478 & 0.225 \\
\hline $\mathrm{B}$ & 1.0 & 42 & 158 & 255 & 2.38 & 3.05 & 478 & 0.252 \\
\hline
\end{tabular}

a The true-stress-strain curve is approximated with $\sigma=F \varepsilon^{n}$.

Table 1. Mechanical properties of sheet materials obtained by a uniaxial tension test. ${ }^{\text {a }}$ 


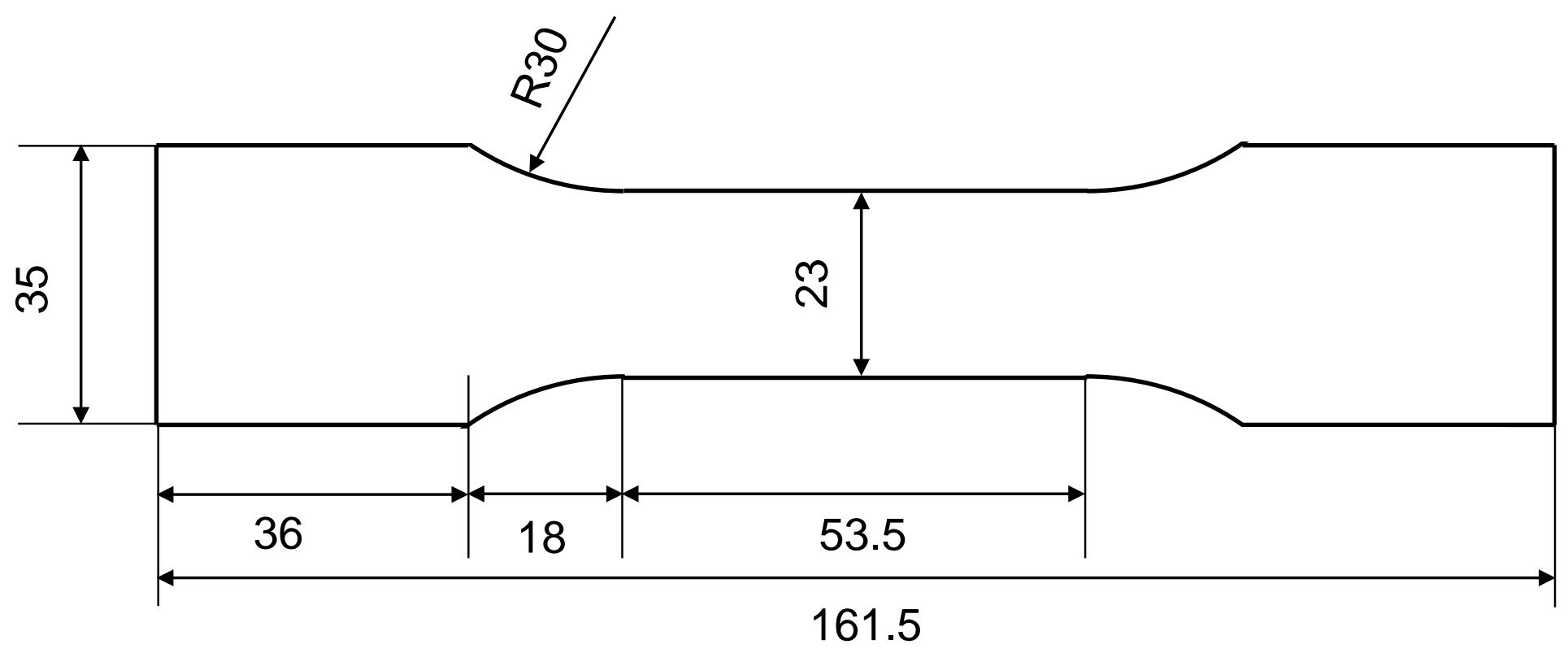

Fig. 1. Geometry of a specimen used in the cyclic loading test. 
Comb-shaped dies

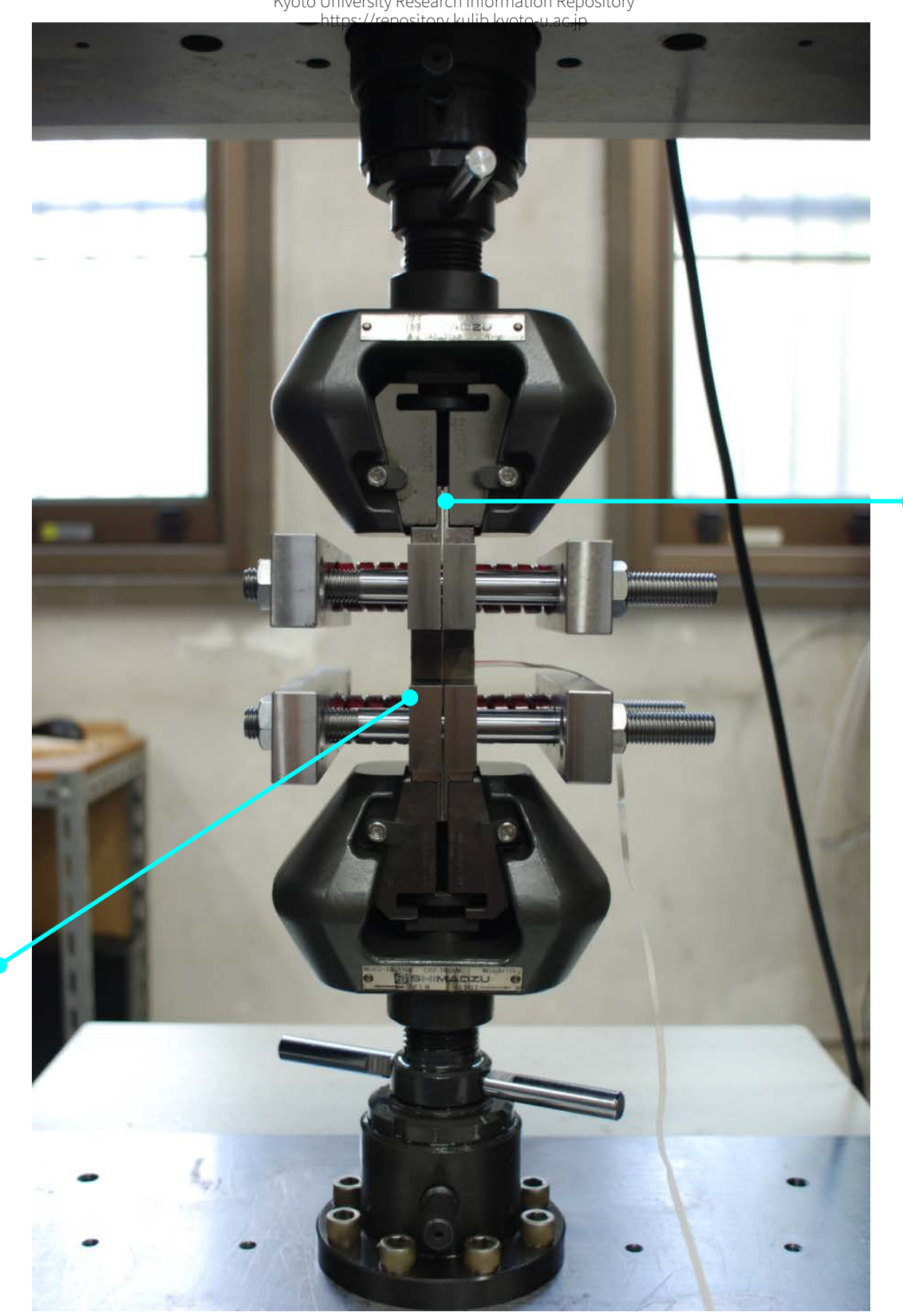

\section{Specimen}

Fig. 2. Photograph of the experimental setup for the cyclic loading test. 


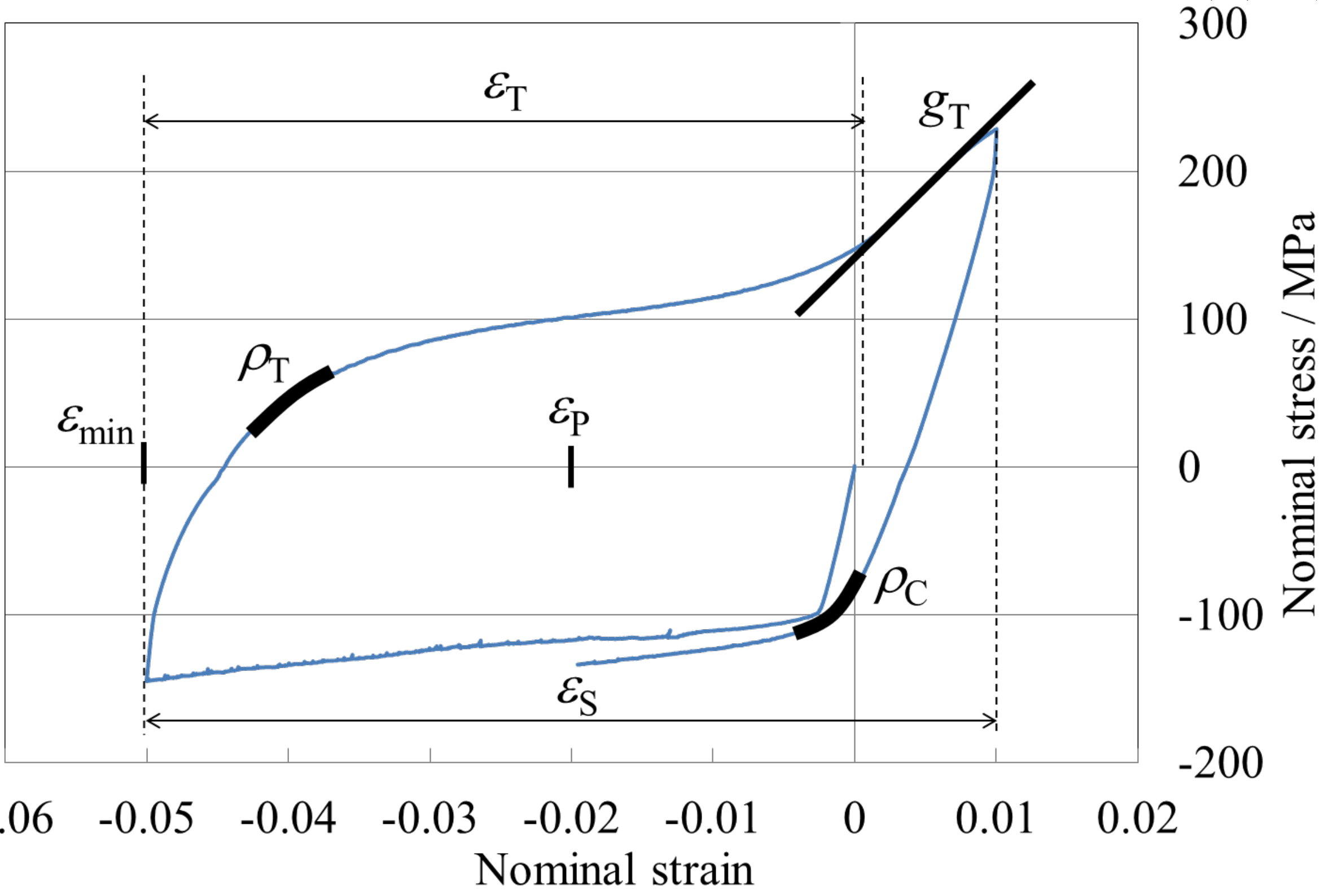

Fig. 3. Symbol definitions. Stress-strain curve of material A with a strain amplitude of $6 \%$ and a pre-strain of $-2 \%$ is shown. 


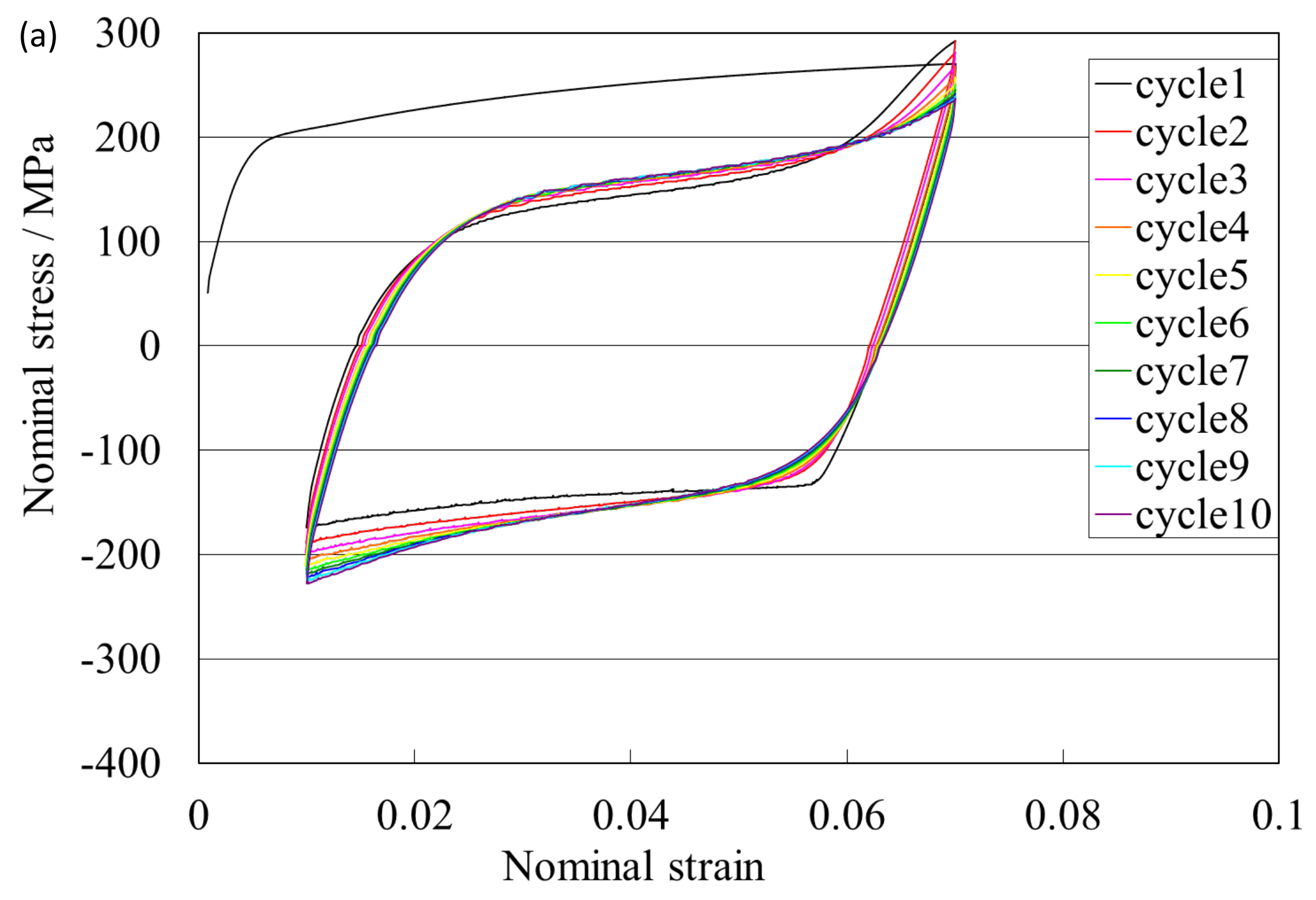

Fig. 4. Stress-strain curves obtained by cyclic loading tests with a strain amplitude of $6 \%$ and pre-strains of (a) 4\%, (b) 0\%, (c) -2\%, (d) -4\%, and (e) -5\%. Material A was used. (The results of (a), (b), and (d) are reproduced from the literature with permission [21].) 


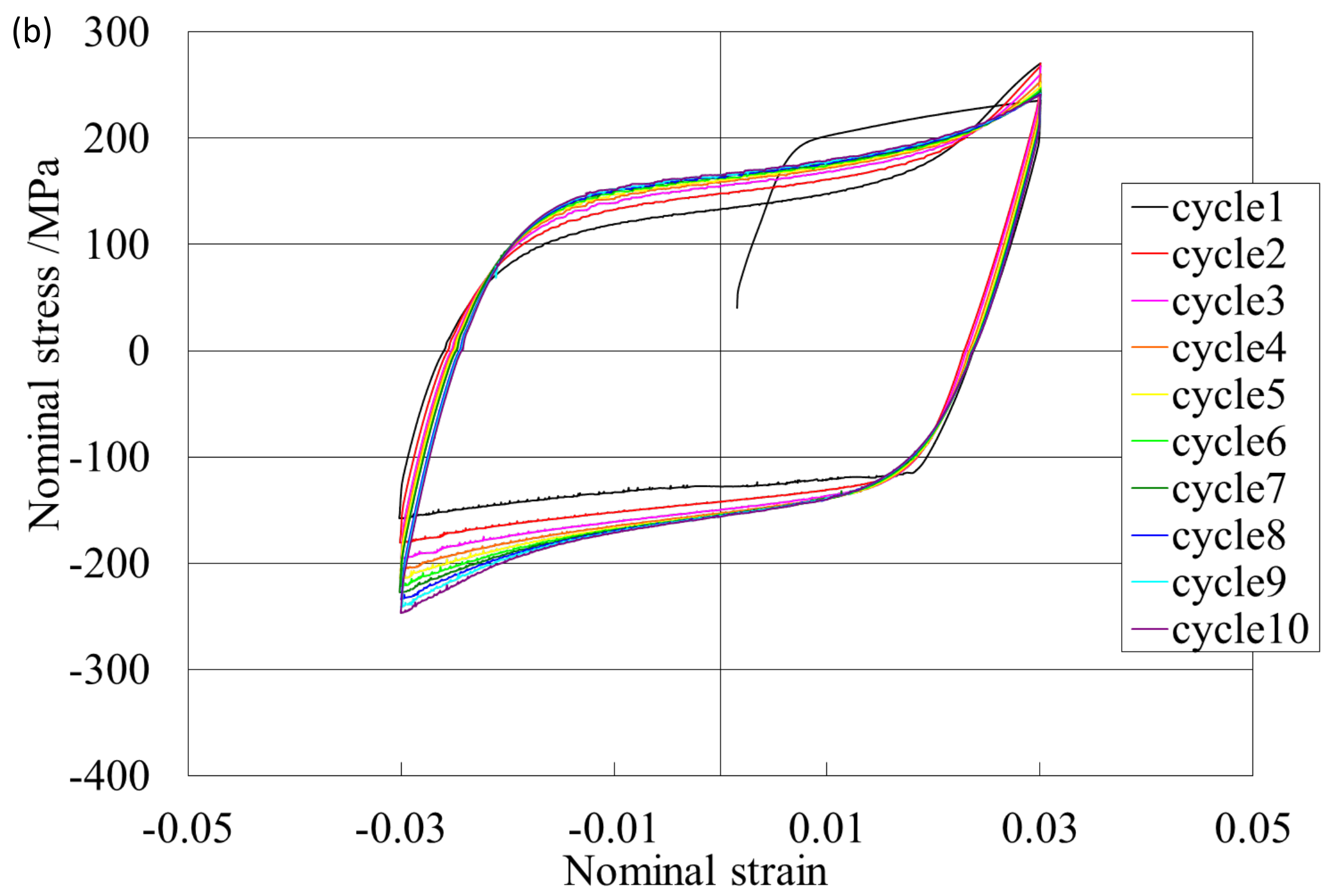

Fig. 4. Stress-strain curves obtained by cyclic loading tests with a strain amplitude of 6\% and pre-strains of (a) 4\%, (b) 0\%, (c) -2\%, (d) -4\%, and (e) -5\%. Material A was used. (The results of (a), (b), and (d) are reproduced from the literature with permission [21].) 


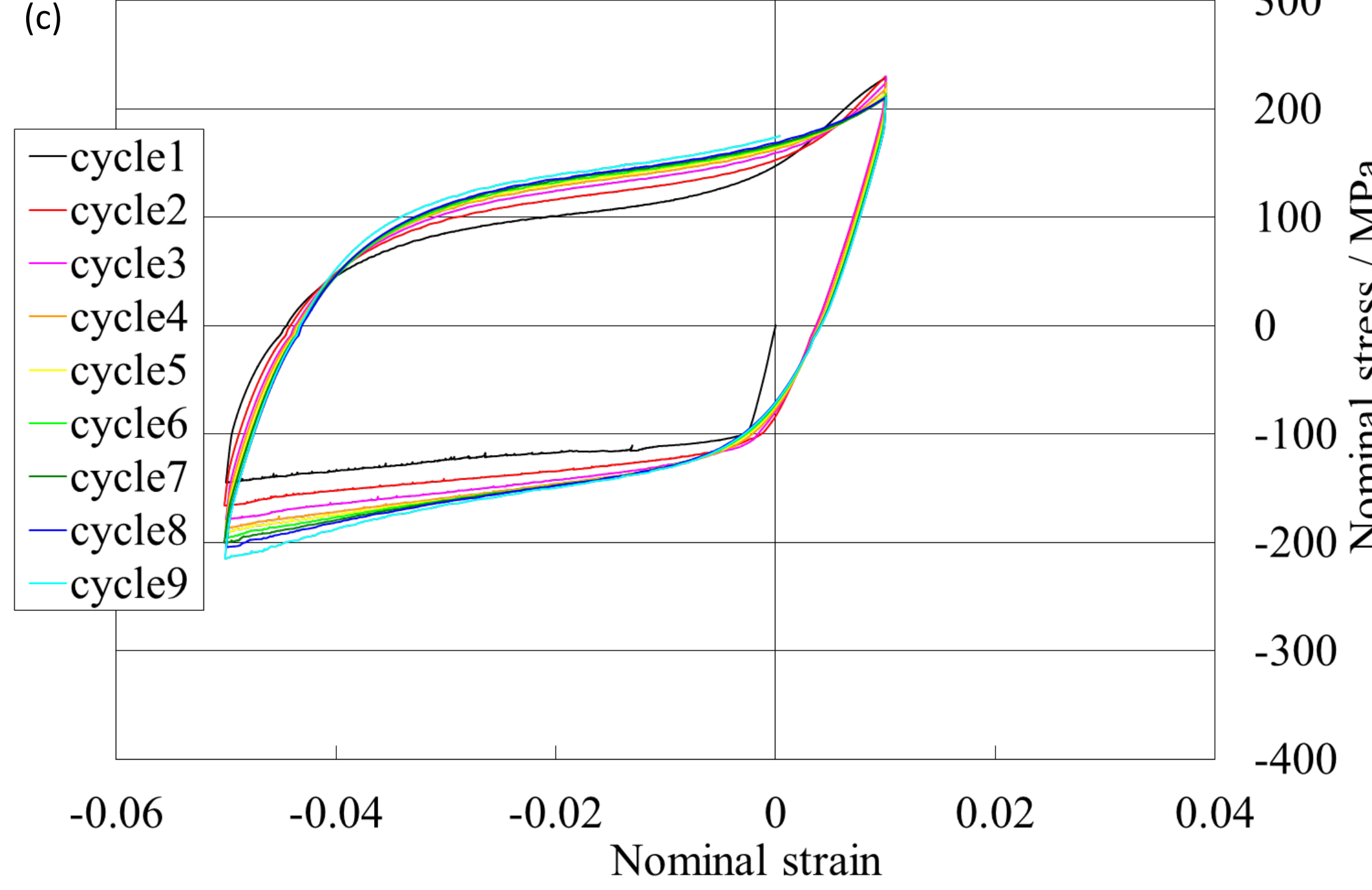

Fig. 4. Stress-strain curves obtained by cyclic loading tests with a strain amplitude of $6 \%$ and pre-strains of (a) 4\%, (b) 0\%, (c) -2\%, (d) -4\%, and (e) -5\%. Material A was used. (The results of (a), (b), and (d) are reproduced from the literature with permission [21].) 
(d)

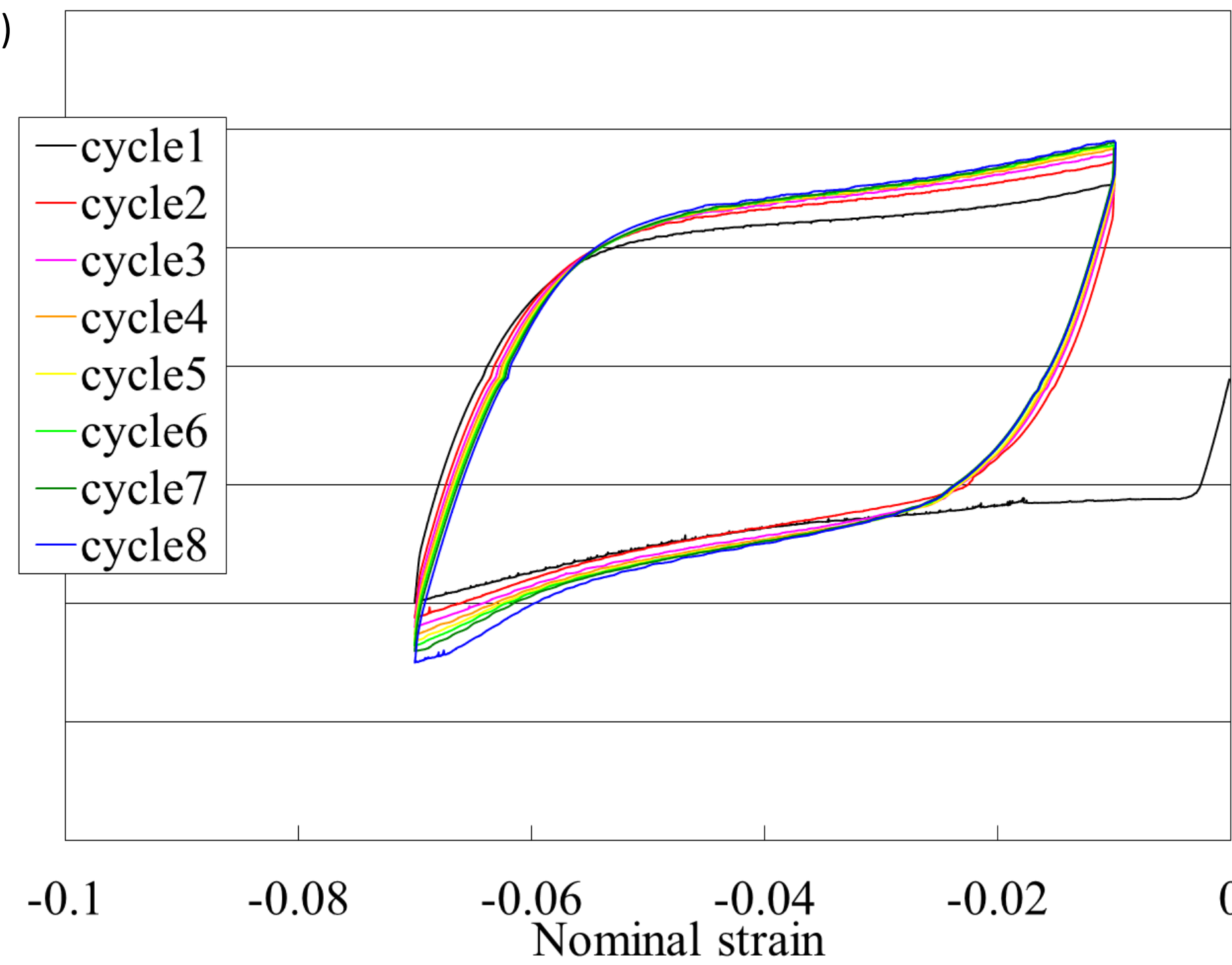

Fig. 4. Stress-strain curves obtained by cyclic loading tests with a strain amplitude of $6 \%$ and pre-strains of (a) $4 \%$, (b) $0 \%$, (c) $-2 \%$, (d) $-4 \%$, and (e) $-5 \%$. Material A was used. (The results of (a), (b), and (d) are reproduced from the literature with permission [21].) 
(e)

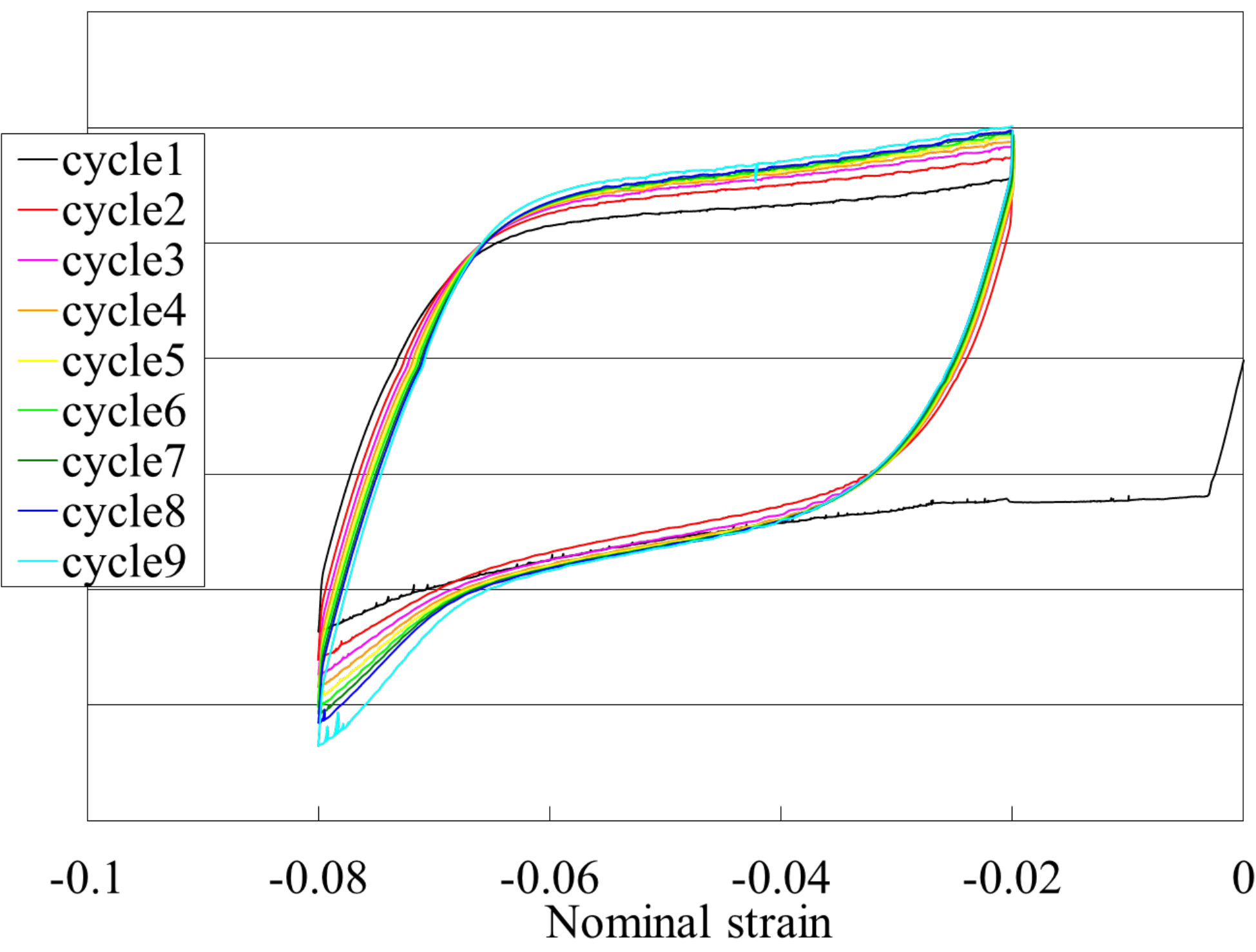

200

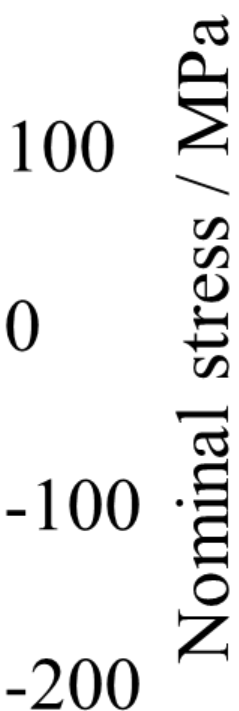

$-300$

$-400$

0

Fig. 4. Stress-strain curves obtained by cyclic loading tests with a strain amplitude of $6 \%$ and pre-strains of (a) $4 \%$, (b) $0 \%$, (c) $-2 \%$, (d) $-4 \%$, and (e) $-5 \%$. Material A was used. (The results of (a), (b), and (d) are reproduced from the literature with permission [21].) 


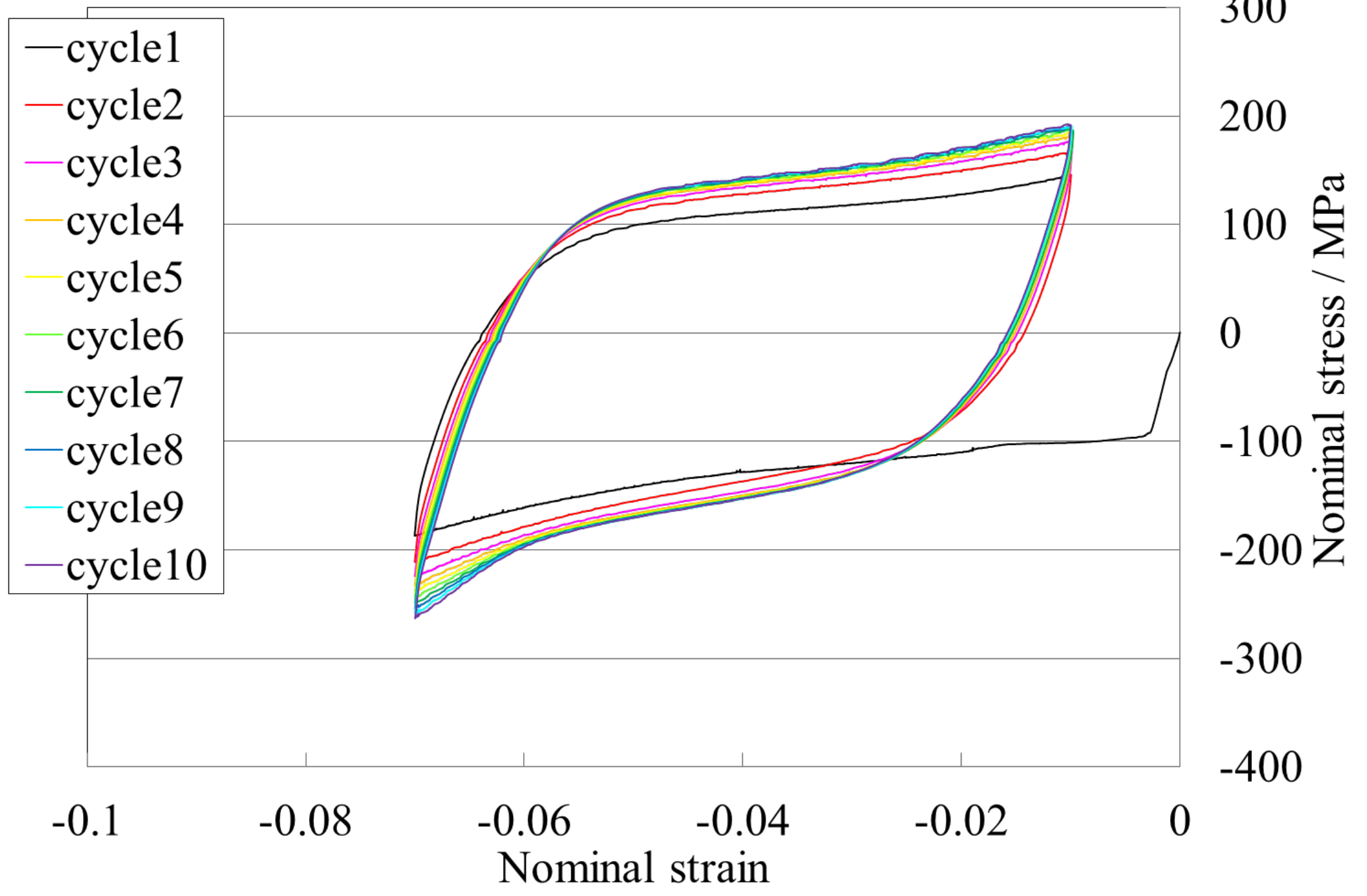

Fig. 5. Stress-strain curve obtained by cyclic loading test with a strain amplitude of $6 \%$ and a pre-strain of $-4 \%$. Material B was used. 


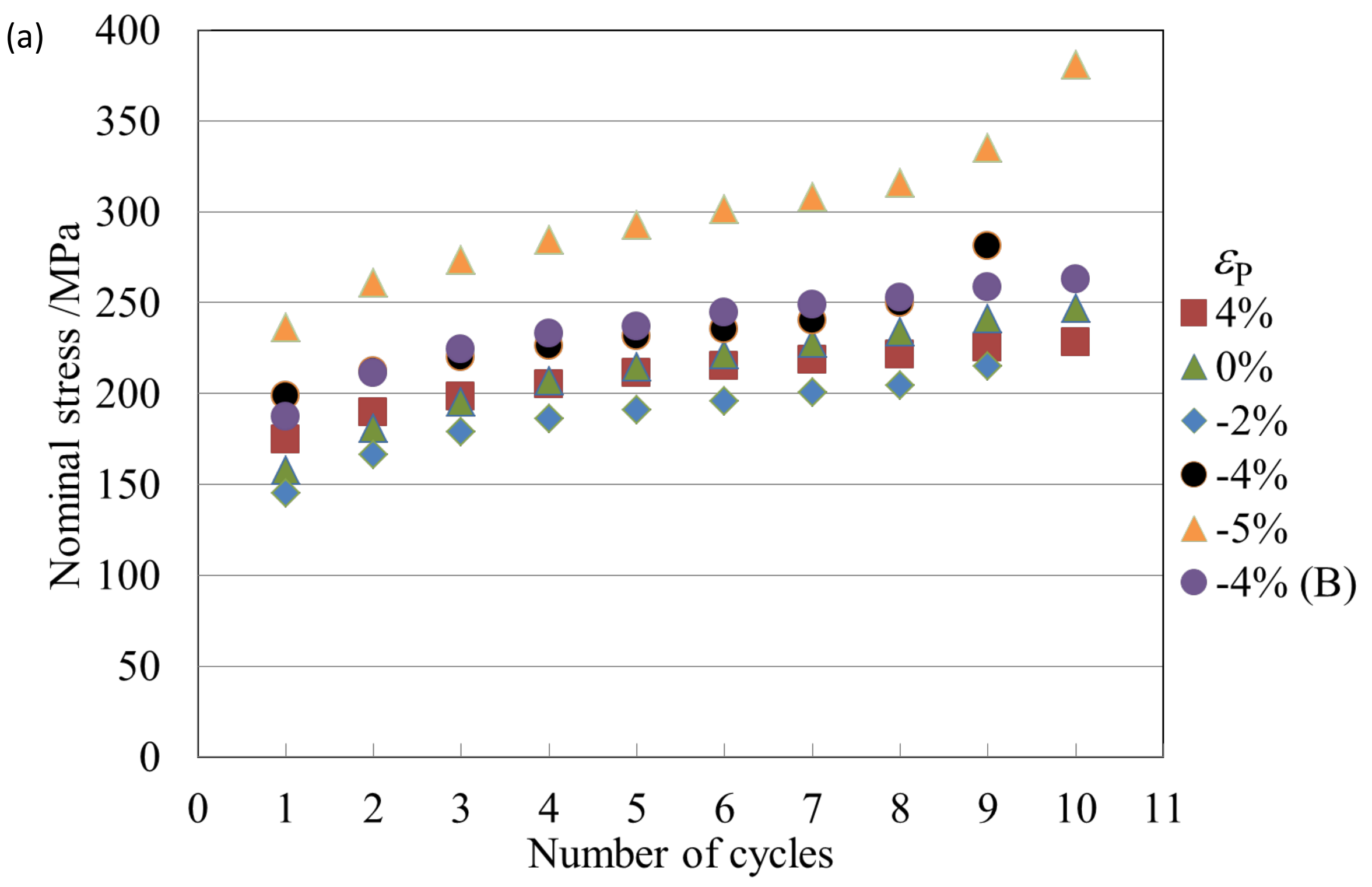

Fig. 6. Changes in stress at the end of tension and compression for the results with a strain amplitude of 6\%: (a) stress at the end of compression and (b) stress at the end of tension. 


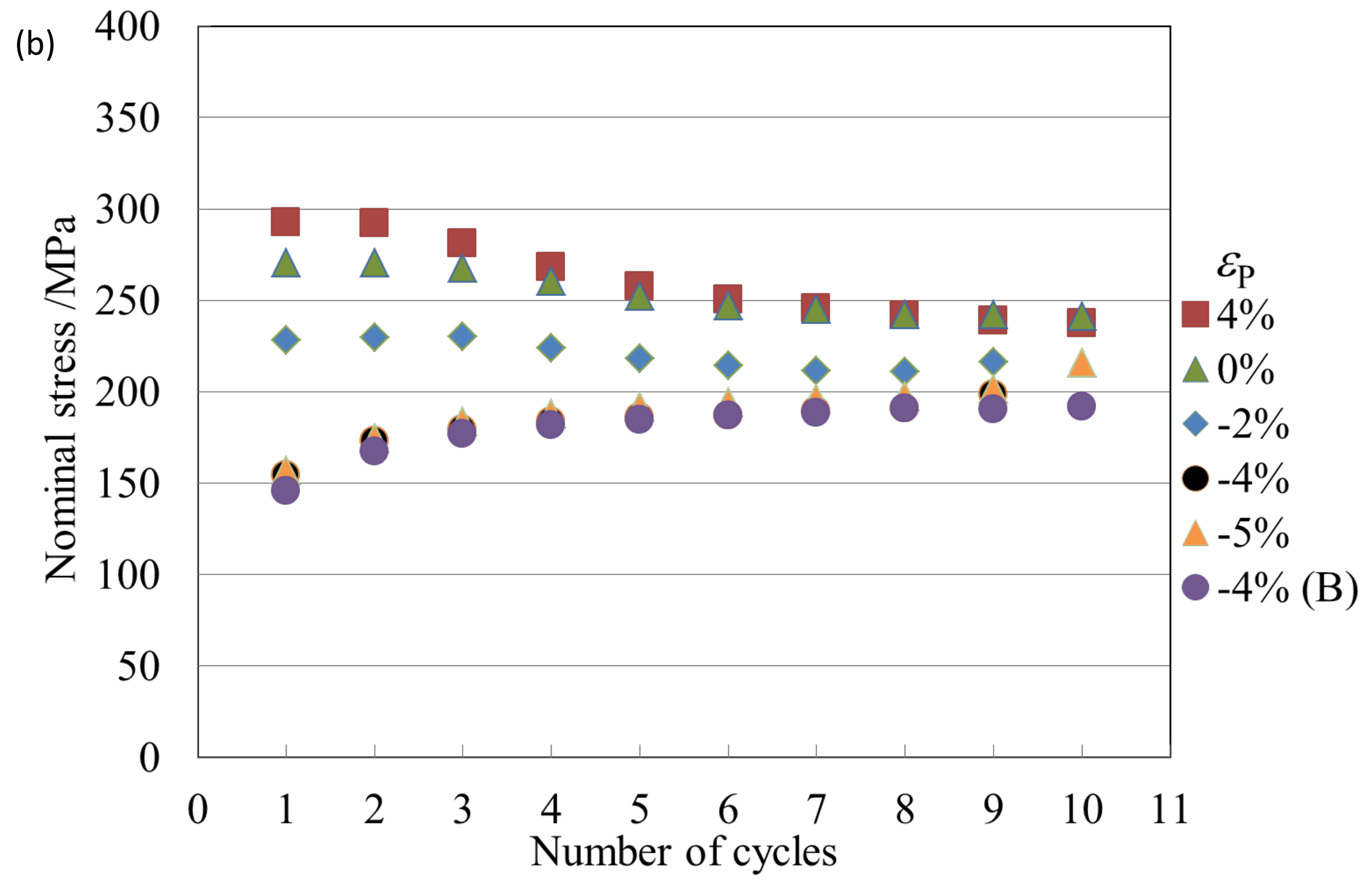

Fig. 6. Changes in stress at the end of tension and compression for the results with a strain amplitude of 6\%: (a) stress at the end of compression and (b) stress at the end of tension. 


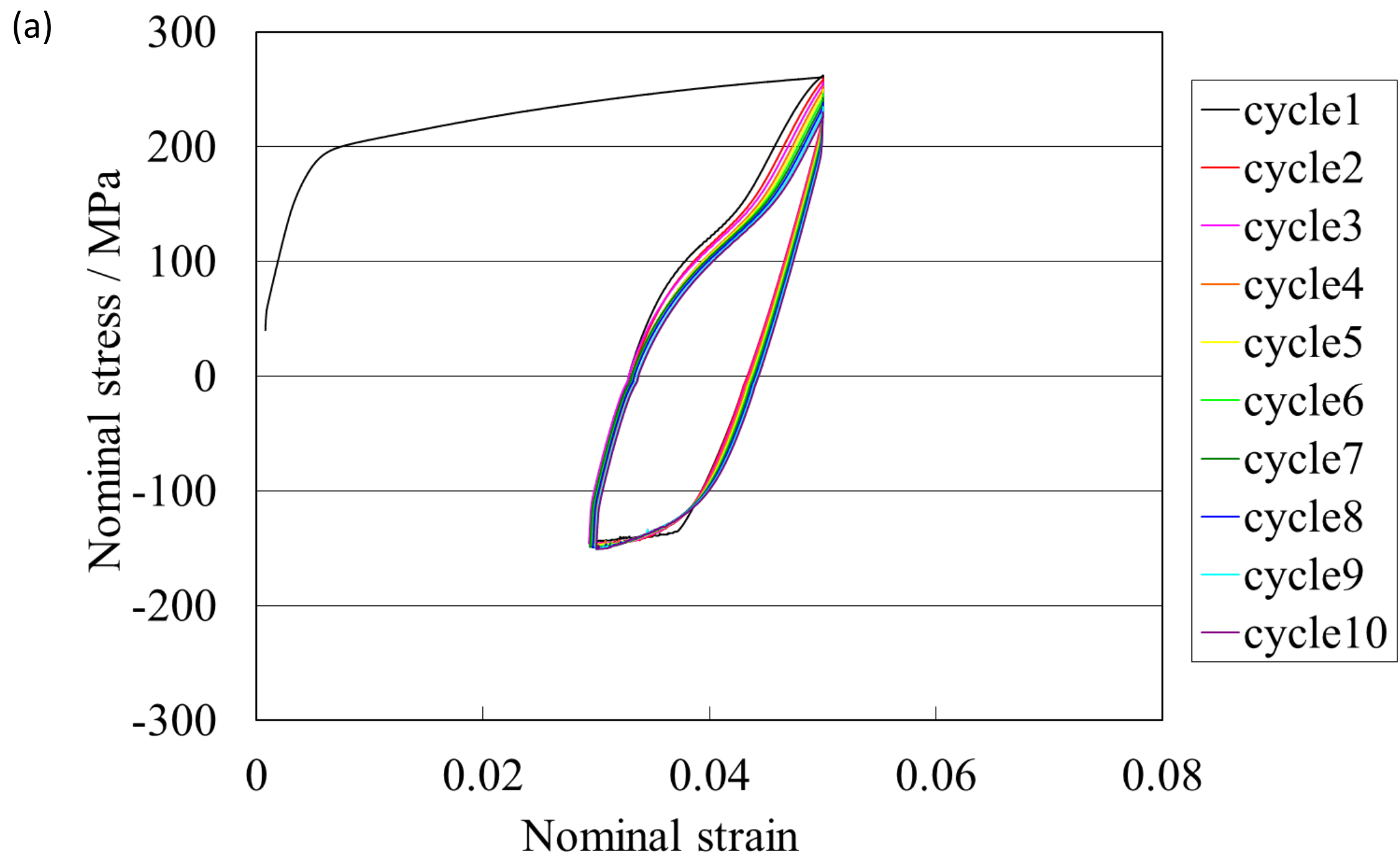

Fig. 7. Stress-strain curves obtained by cyclic loading tests with a strain amplitude of $2 \%$ and pre-strains of (a) $4 \%$, (b) $0 \%$, (c) $-2 \%$, (d) $-4 \%$, (e) $-5 \%$, and (f) $-6 \%$. Material A was used. 


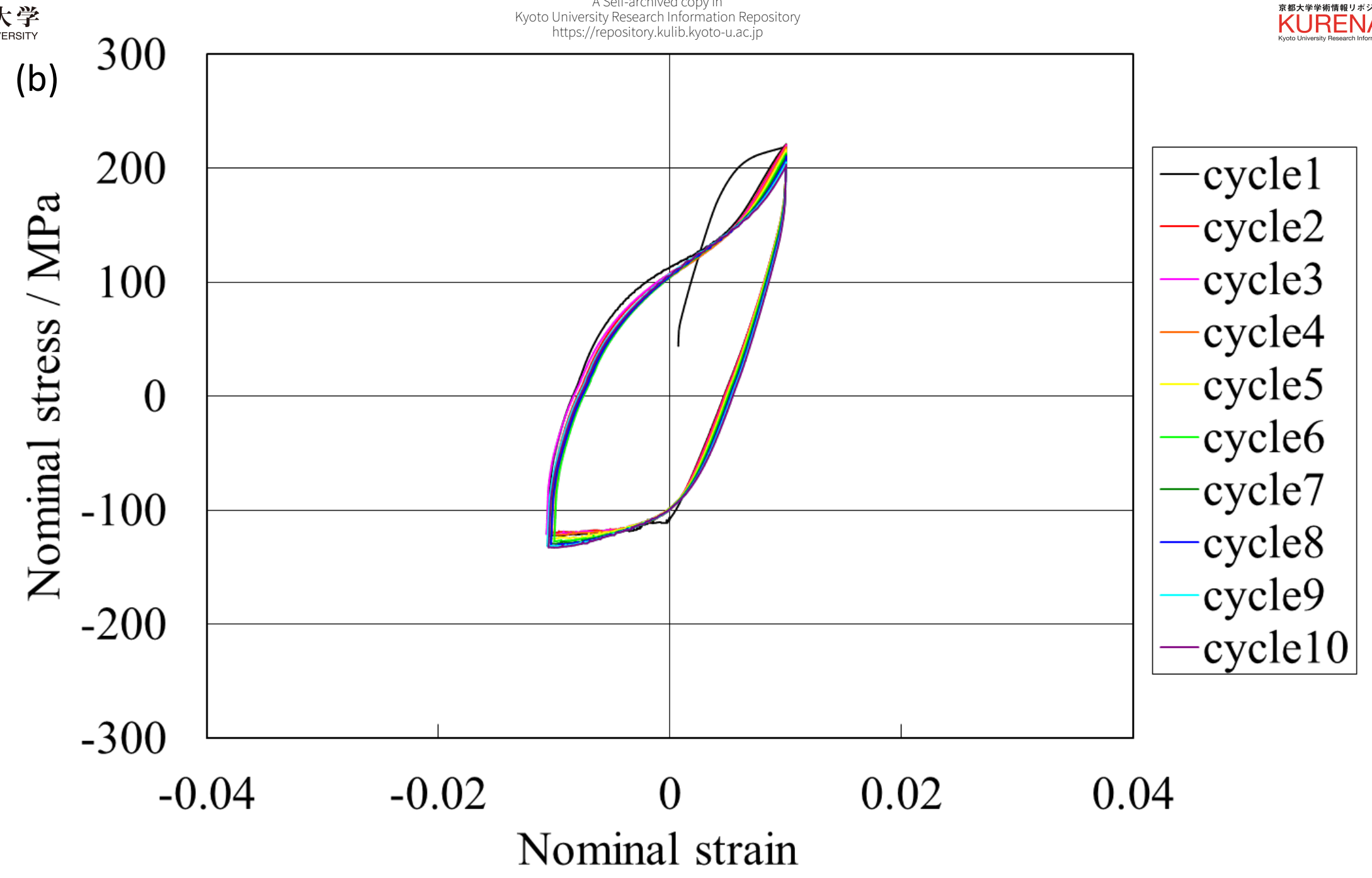

Fig. 7. Stress-strain curves obtained by cyclic loading tests with a strain amplitude of $2 \%$ and pre-strains of (a) $4 \%$, (b) $0 \%$, (c) $-2 \%$, (d) $-4 \%$, (e) $-5 \%$, and (f) $-6 \%$. Material A was used. 
(c)

\begin{tabular}{|l|}
\hline - cycle1 \\
- cycle2 \\
- cycle3 \\
- cycle4 \\
cycle5 \\
- cycle6 \\
- cycle7 \\
- cycle8 \\
- cycle9 \\
- cycle10
\end{tabular}

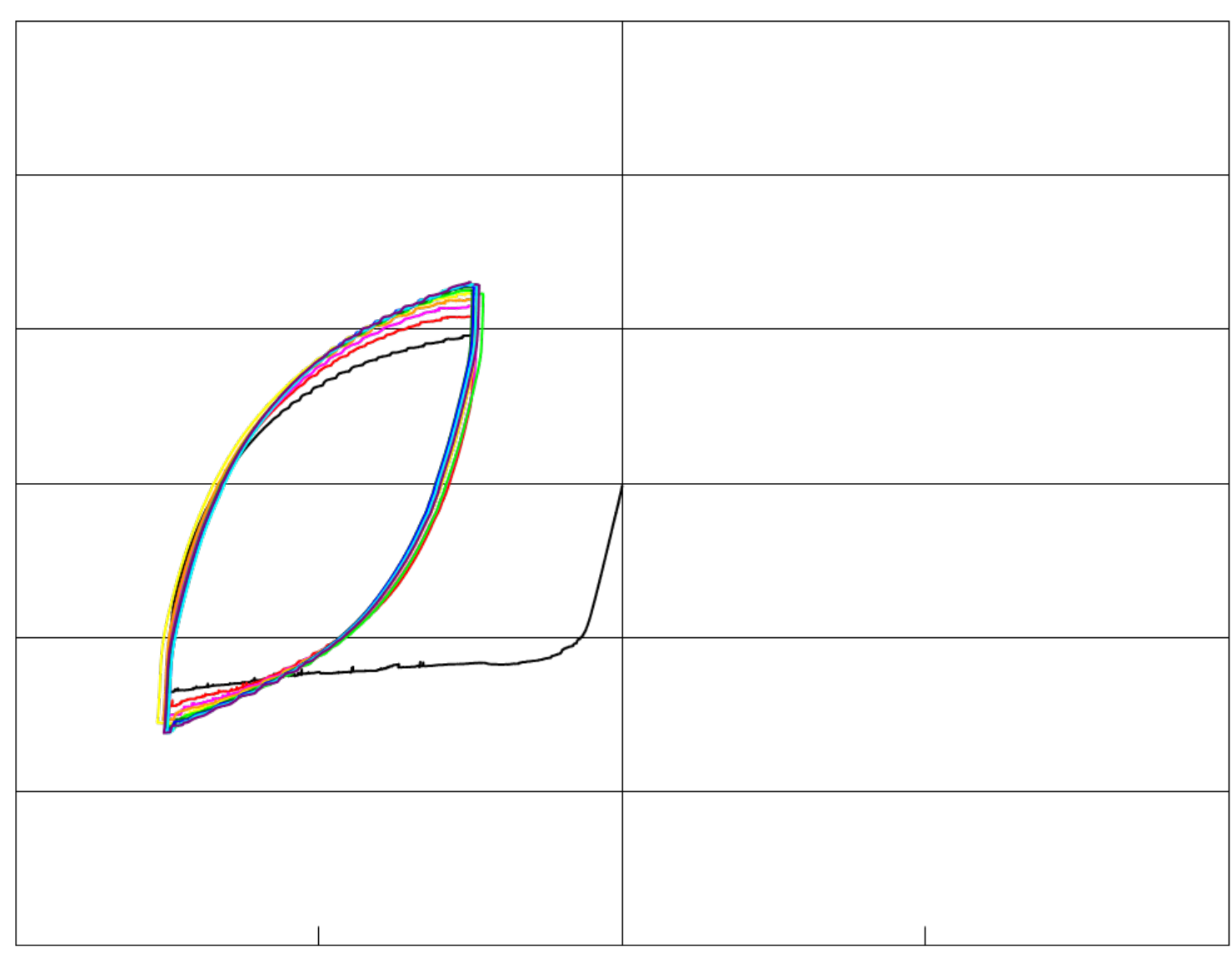

300

200

$100 \stackrel{\Xi}{\Sigma}$

0

品

-100 胥

$-200$

$-300$

$-0.04$

$-0.02$

0

0.02

Nominal strain

Fig. 7. Stress-strain curves obtained by cyclic loading tests with a strain amplitude of $2 \%$ and pre-strains of (a) 4\%, (b) $0 \%$, (c) $-2 \%$, (d) $-4 \%$, (e) $-5 \%$, and (f) $-6 \%$. Material A was used. 


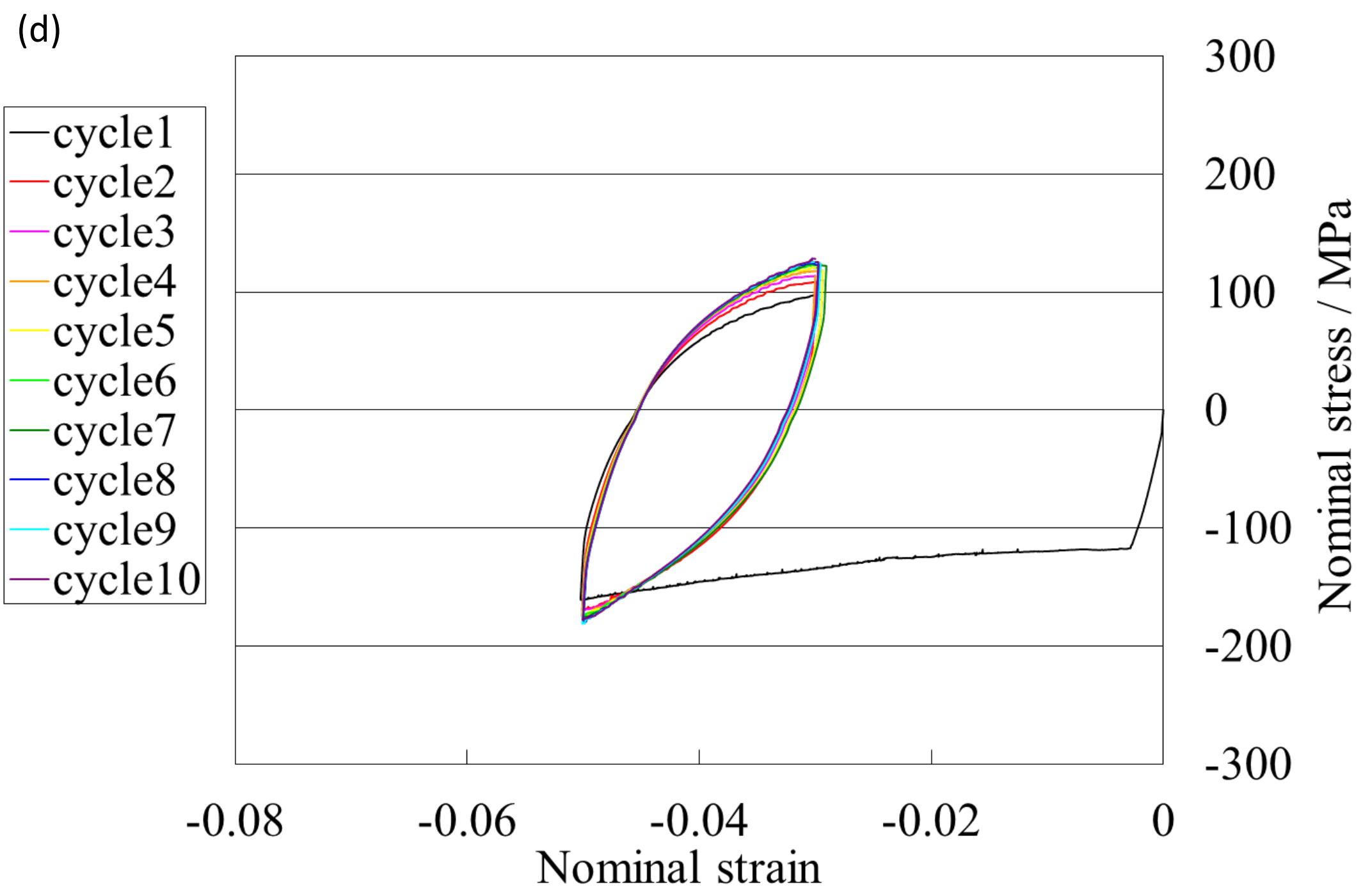

Fig. 7. Stress-strain curves obtained by cyclic loading tests with a strain amplitude of $2 \%$ and pre-strains of (a) 4\%, (b) $0 \%$, (c) $-2 \%$, (d) $-4 \%$, (e) $-5 \%$, and (f) $-6 \%$. Material A was used. 


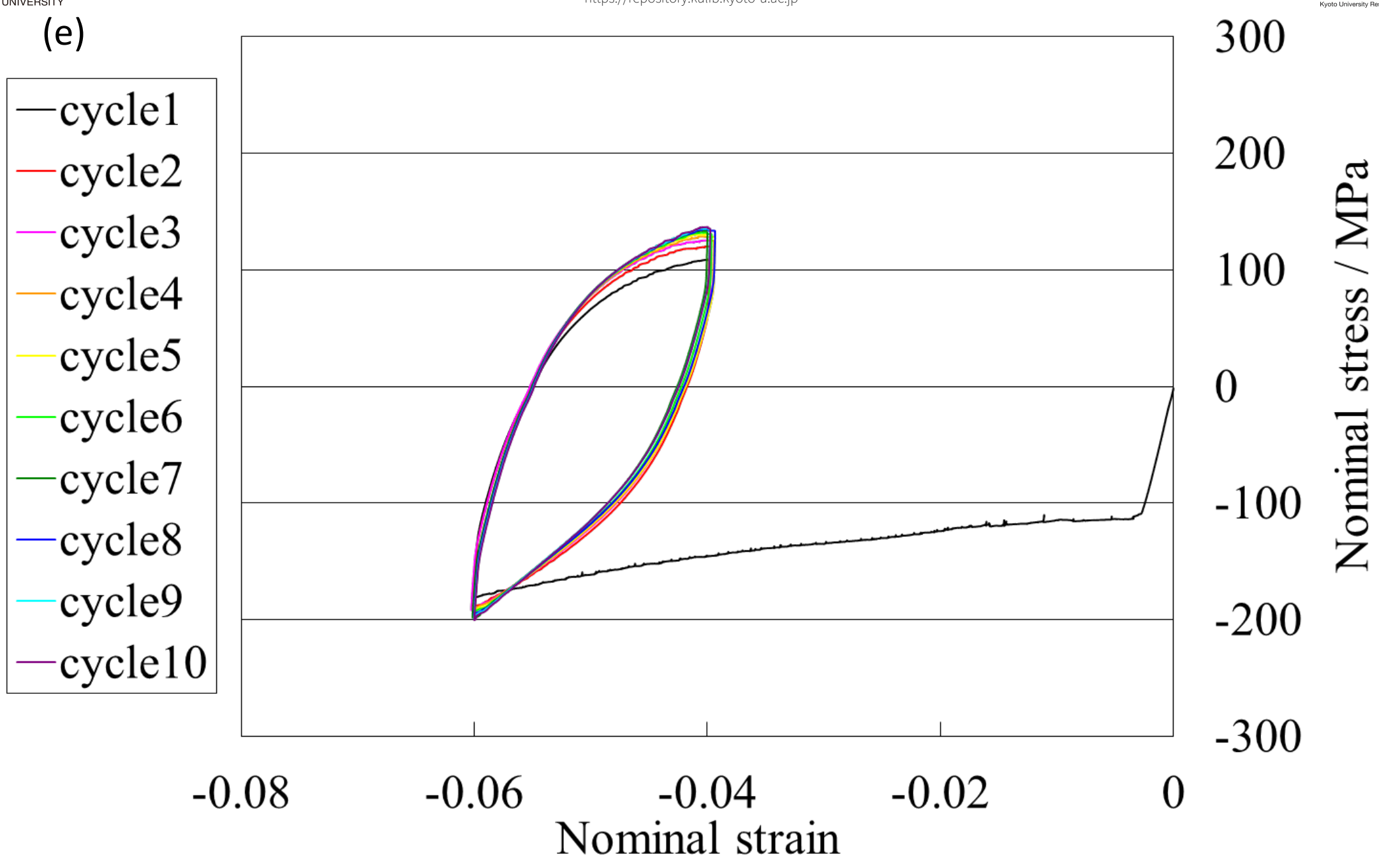

Fig. 7. Stress-strain curves obtained by cyclic loading tests with a strain amplitude of $2 \%$ and pre-strains of (a) 4\%, (b) $0 \%$, (c) $-2 \%$, (d) $-4 \%$, (e) $-5 \%$, and (f) $-6 \%$. Material A was used. 
-cycle1

- cycle2

- cycle3

- cycle4 cycle5

- cycle6

- cycle7

- cycle8

- cycle9

- cycle10
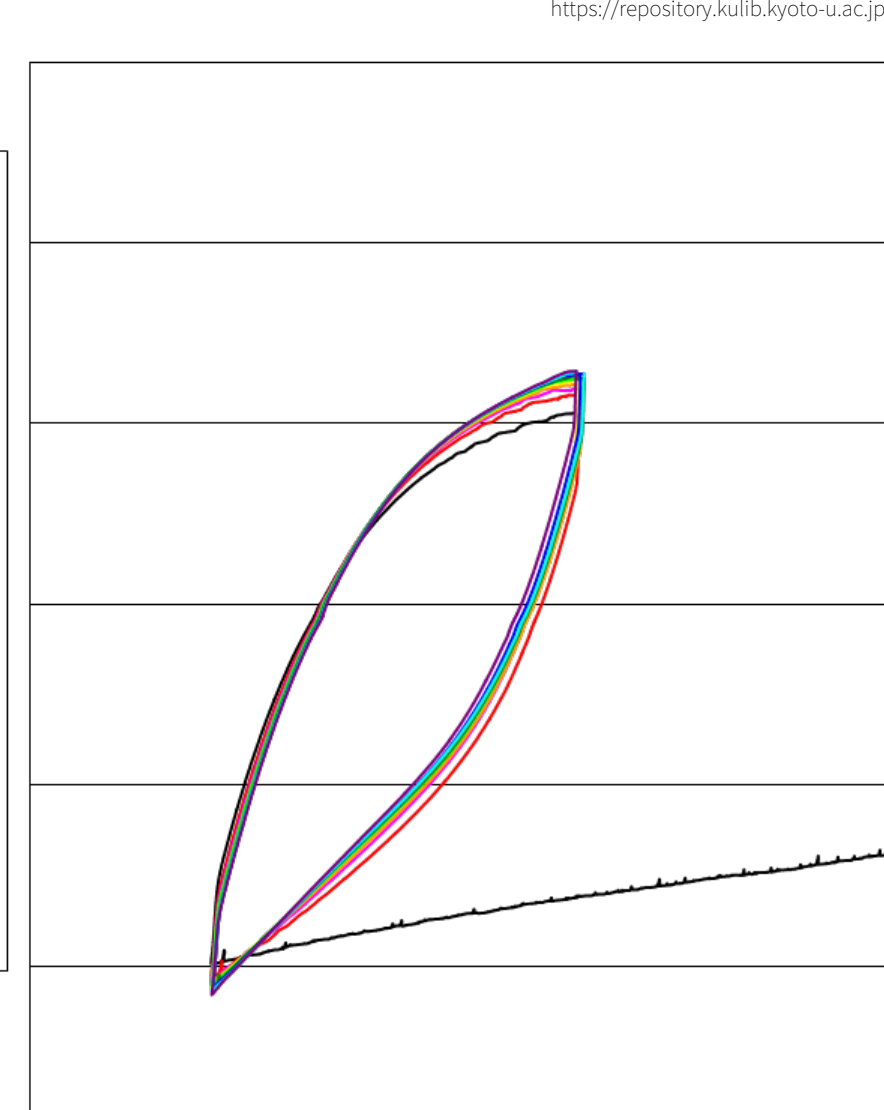

200

200
100

$\sum^{\sigma}$

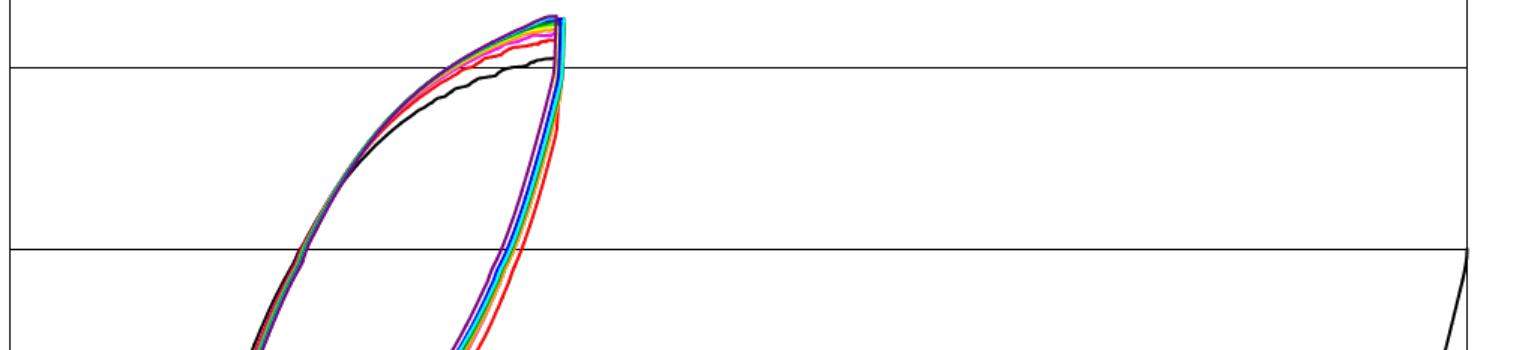

0

点

$-100$

节

$-200$

$-300$

$-0.08$

$-0.06$

$-0.04$

$-0.02$

0

Nominal strain

Fig. 7. Stress-strain curves obtained by cyclic loading tests with a strain amplitude of $2 \%$ and pre-strains of (a) 4\%, (b) $0 \%$, (c) $-2 \%$, (d) $-4 \%$, (e) $-5 \%$, and (f) $-6 \%$. Material A was used. 


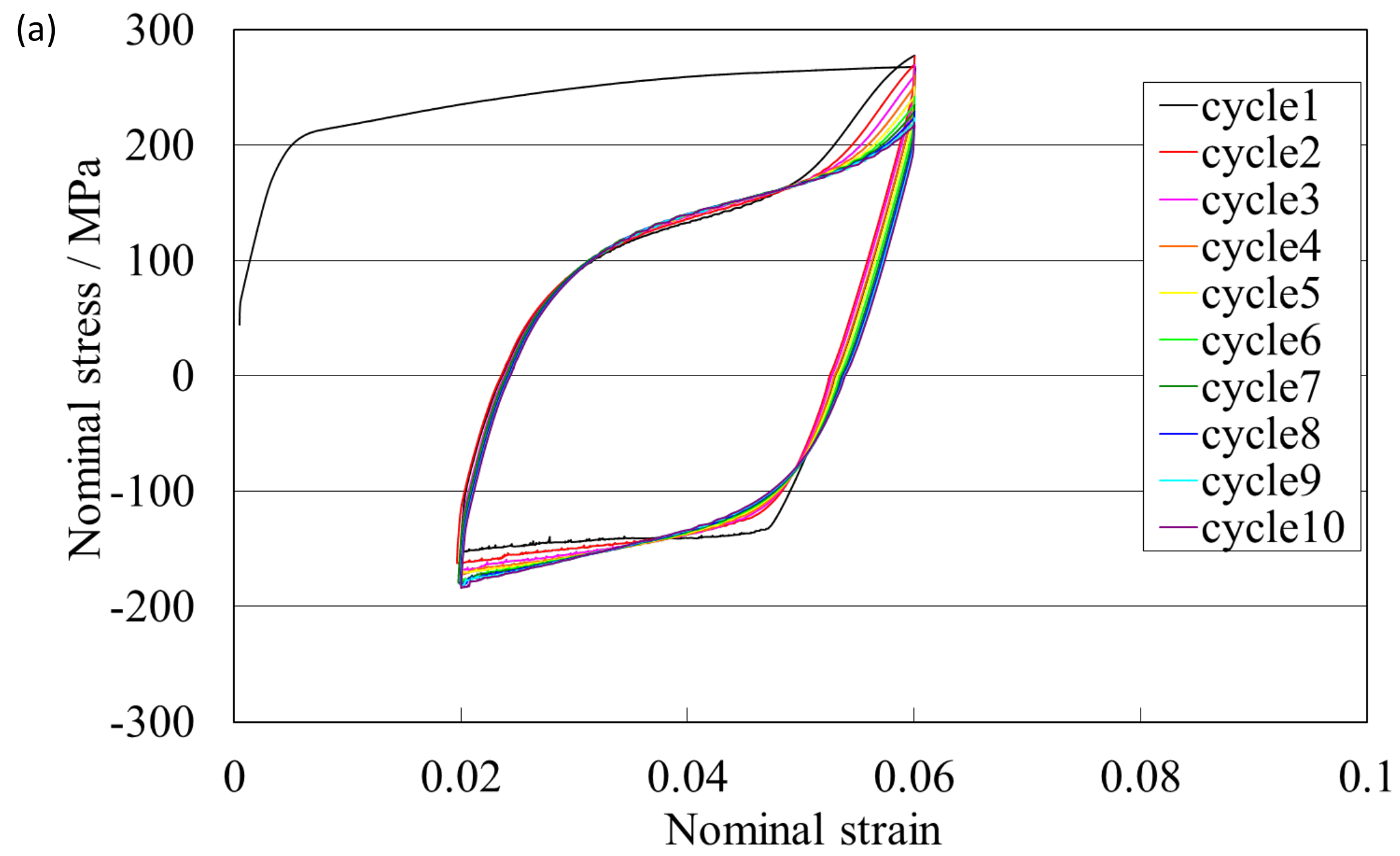

Fig. 8. Stress-strain curves obtained by cyclic loading tests with a strain amplitude of $4 \%$ and pre-strains of (a) 4\%, (b) $0 \%$, (c) $-2 \%$, (d) $-4 \%$, (e) $-5 \%$, and (f) $-6 \%$. Material A was used. 


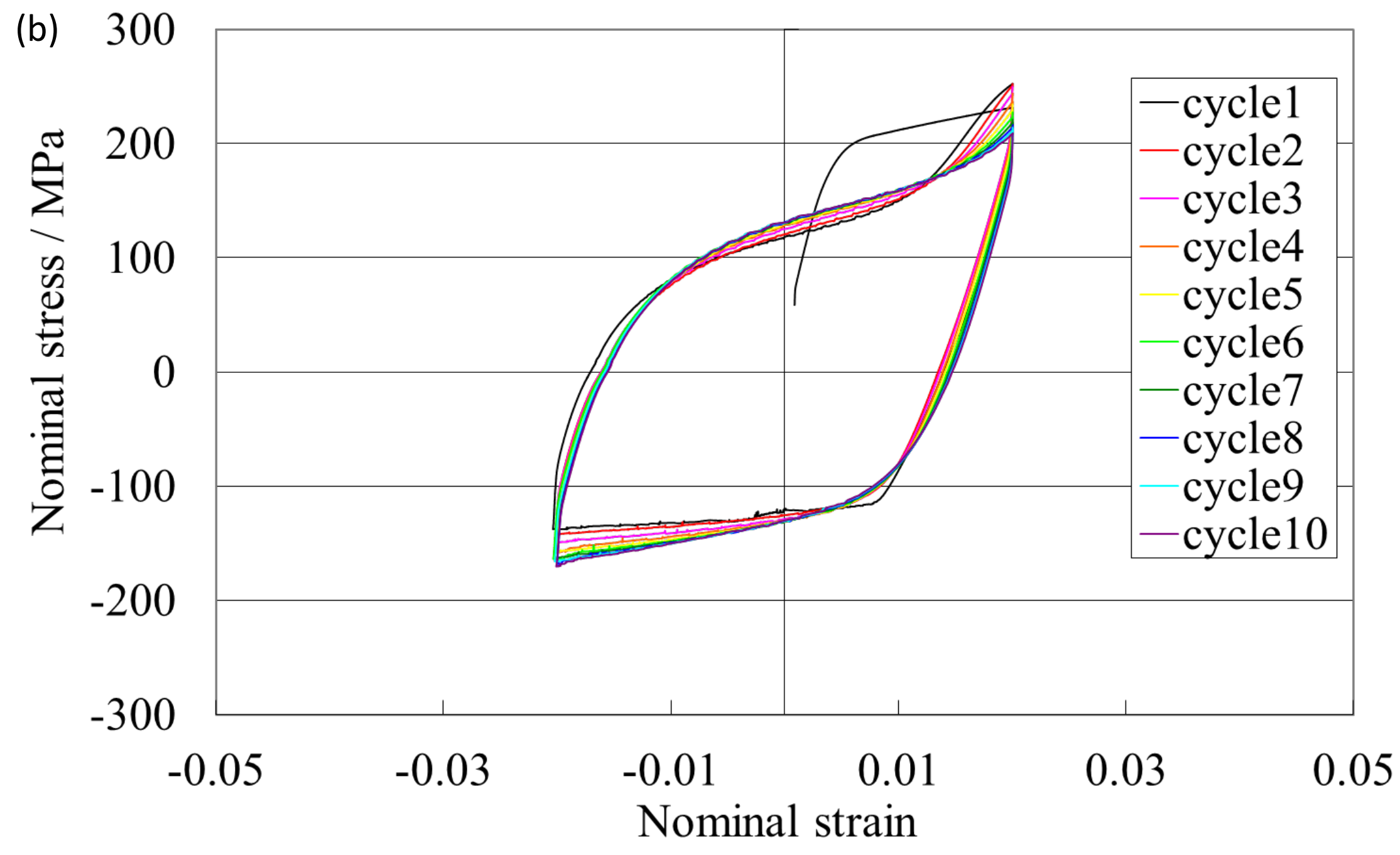

Fig. 8. Stress-strain curves obtained by cyclic loading tests with a strain amplitude of $4 \%$ and pre-strains of (a) 4\%, (b) $0 \%$, (c) $-2 \%$, (d) $-4 \%$, (e) $-5 \%$, and (f) $-6 \%$. Material A was used. 
(c)

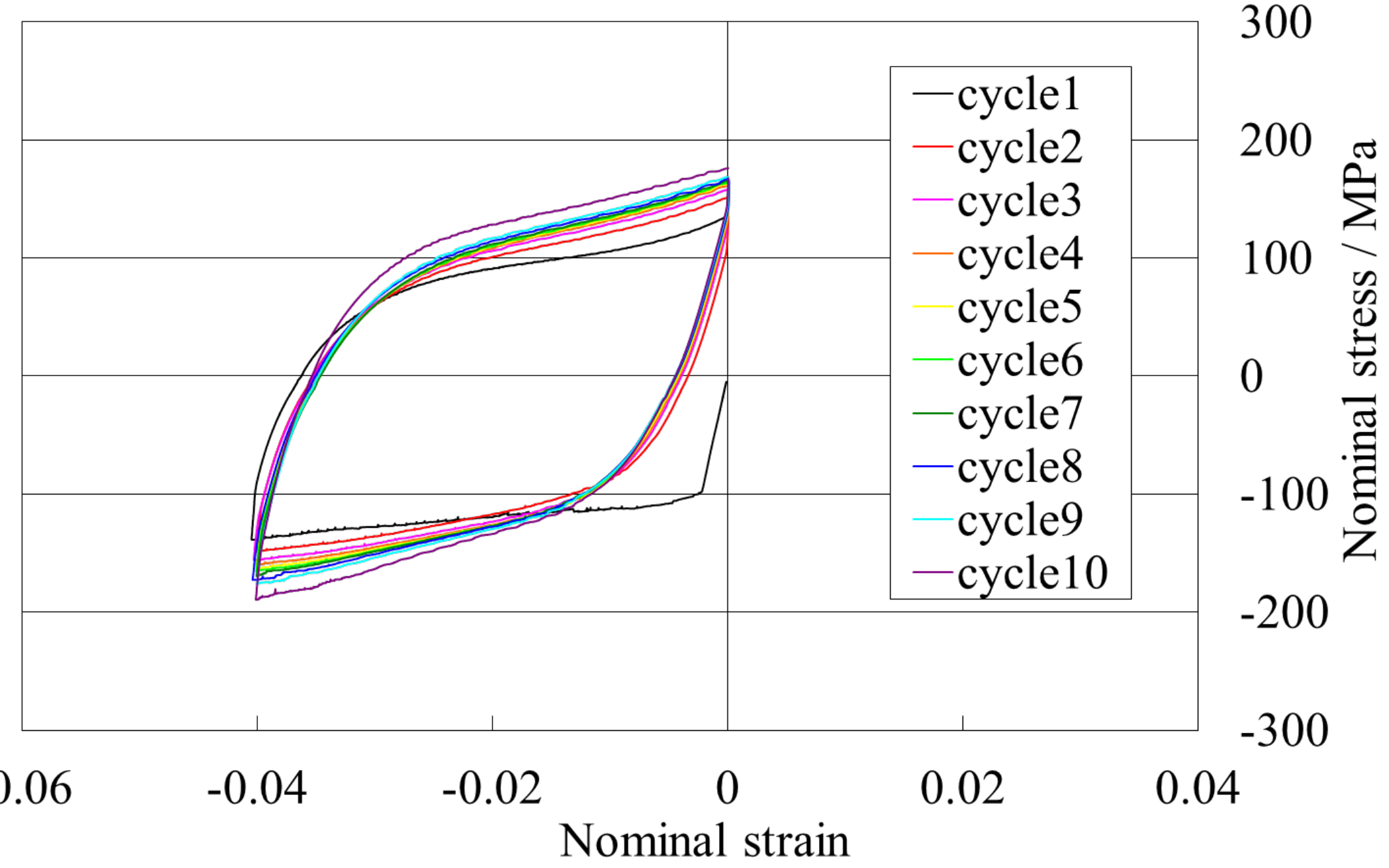

Fig. 8. Stress-strain curves obtained by cyclic loading tests with a strain amplitude of $4 \%$ and pre-strains of (a) $4 \%$, (b) $0 \%$, (c) $-2 \%$, (d) $-4 \%$, (e) $-5 \%$, and (f) $-6 \%$. Material A was used. 
(d)

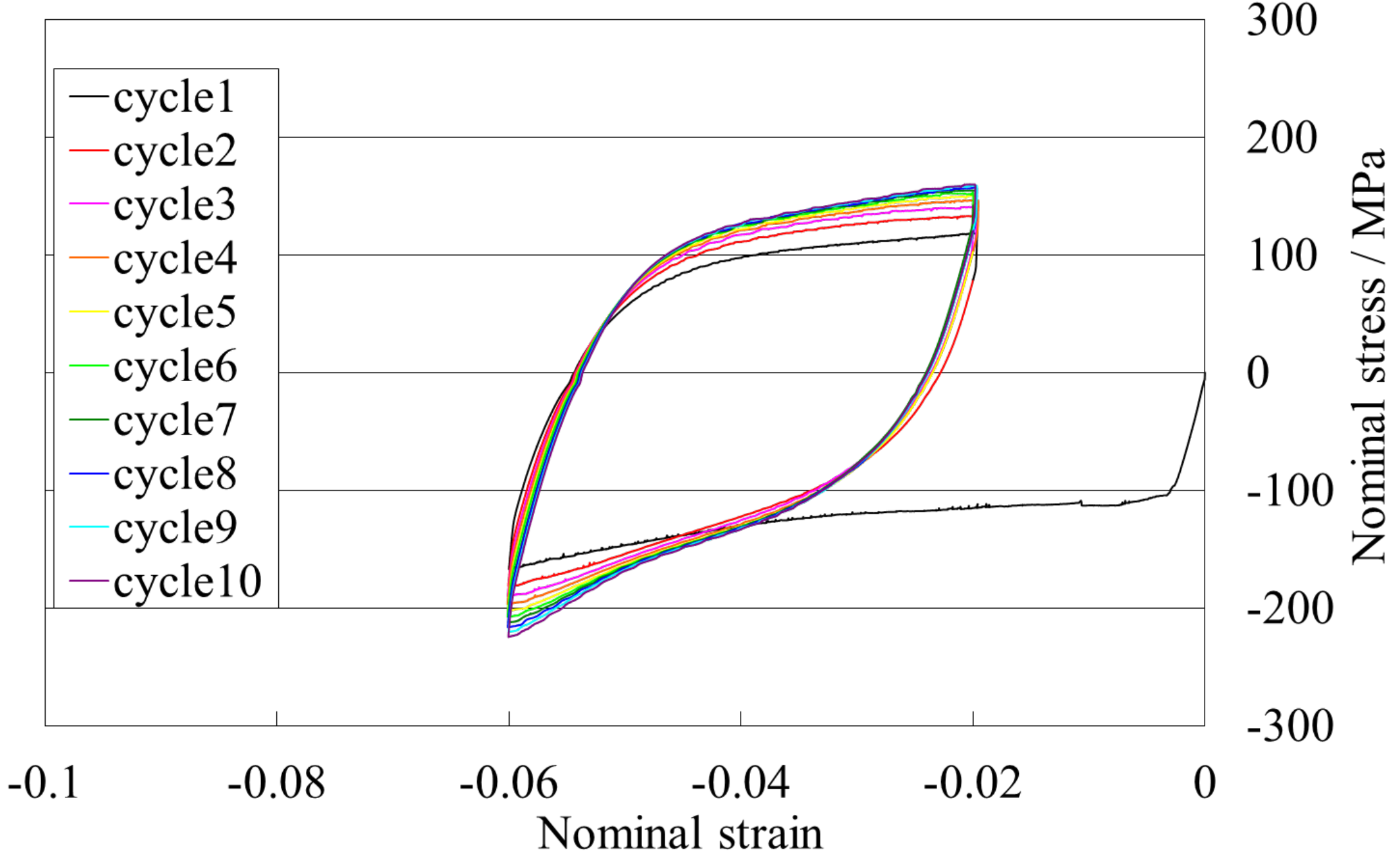

Fig. 8. Stress-strain curves obtained by cyclic loading tests with a strain amplitude of $4 \%$ and pre-strains of (a) 4\%, (b) $0 \%$, (c) $-2 \%$, (d) $-4 \%$, (e) $-5 \%$, and (f) $-6 \%$. Material A was used. 
(e)

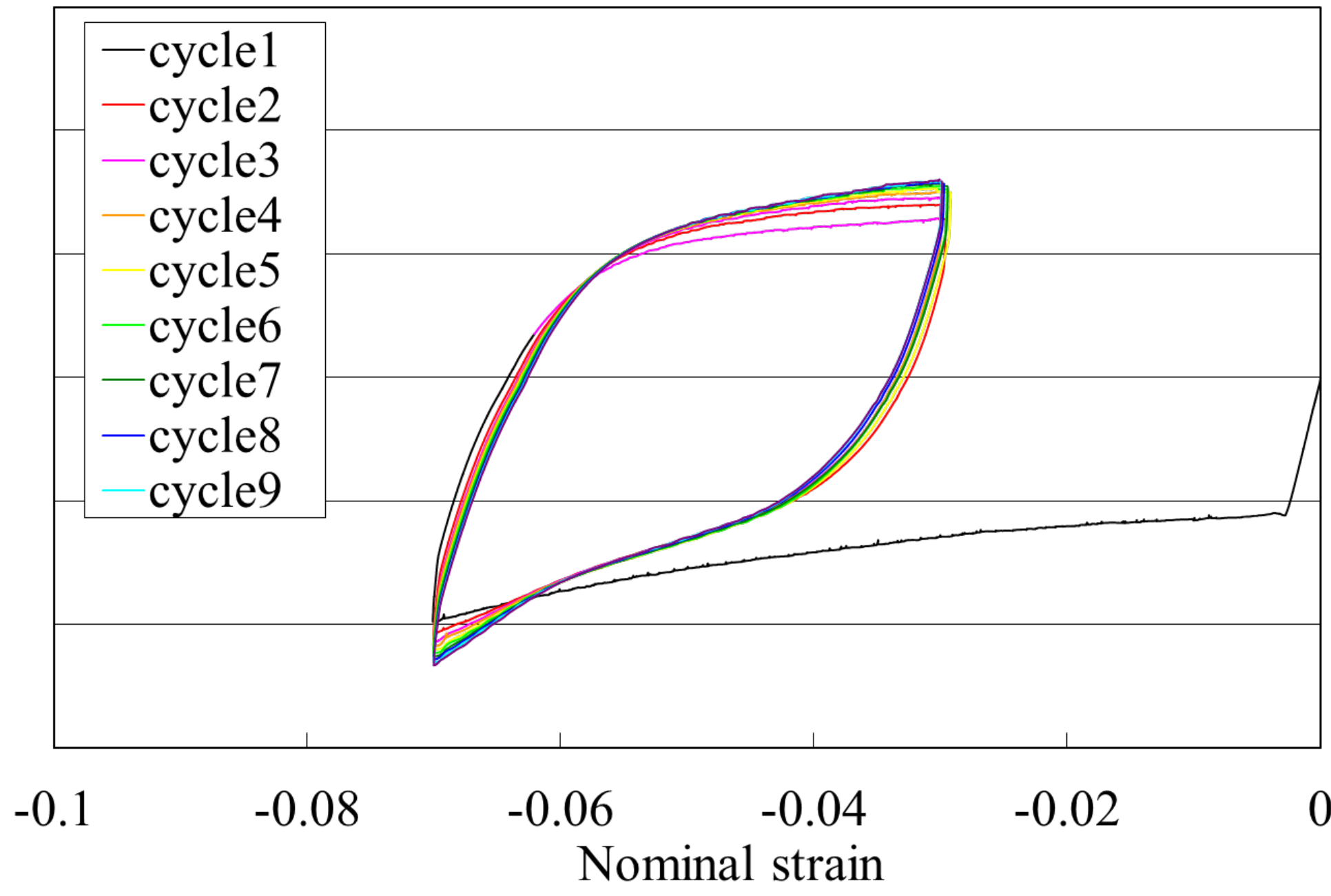

Fig. 8. Stress-strain curves obtained by cyclic loading tests with a strain amplitude of $4 \%$ and pre-strains of (a) 4\%, (b) $0 \%$, (c) $-2 \%$, (d) $-4 \%$, (e) $-5 \%$, and (f) $-6 \%$. Material A was used. 


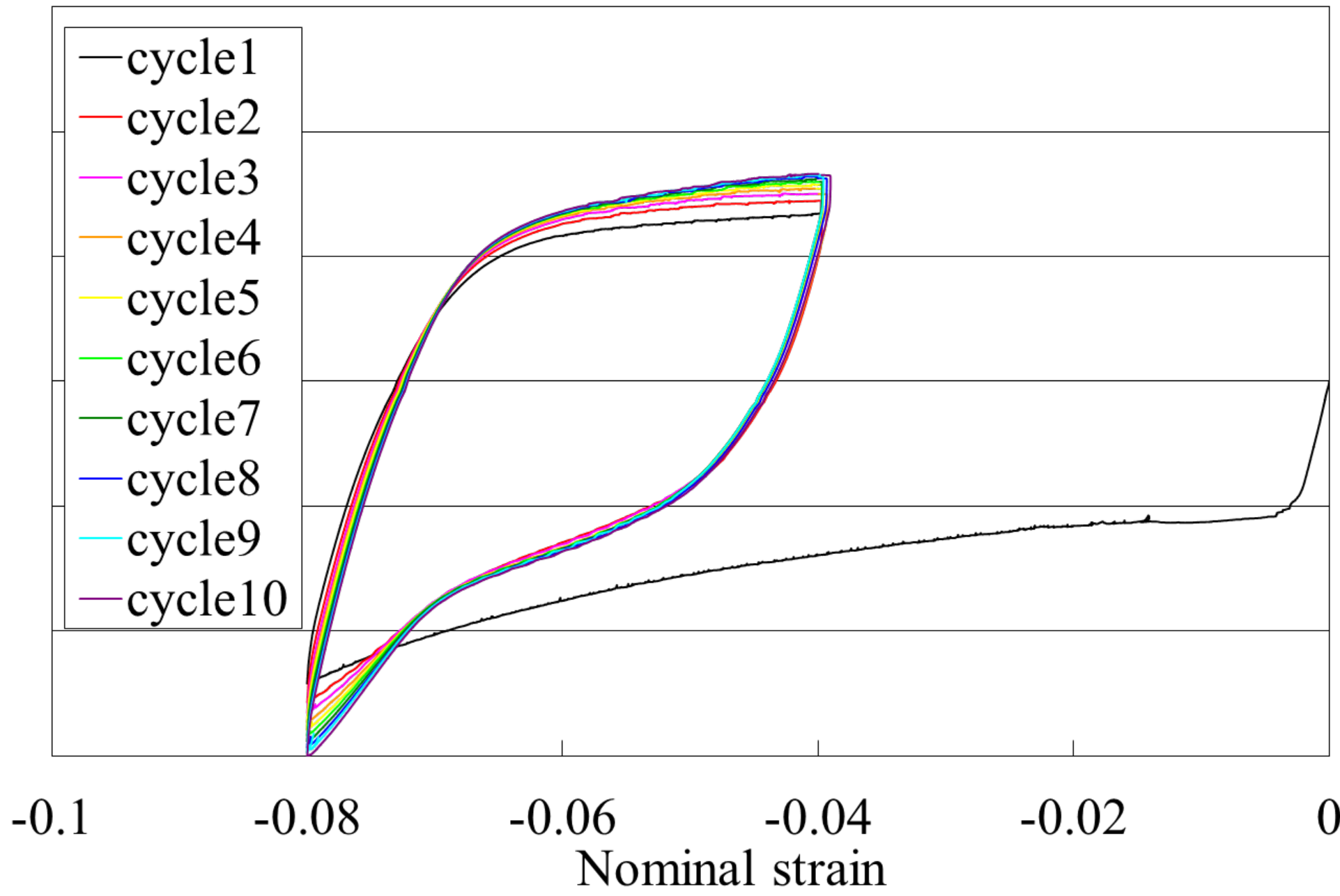

Fig. 8. Stress-strain curves obtained by cyclic loading tests with a strain amplitude of $4 \%$ and pre-strains of (a) 4\%, (b) $0 \%$, (c) $-2 \%$, (d) $-4 \%$, (e) $-5 \%$, and (f) $-6 \%$. Material A was used. 


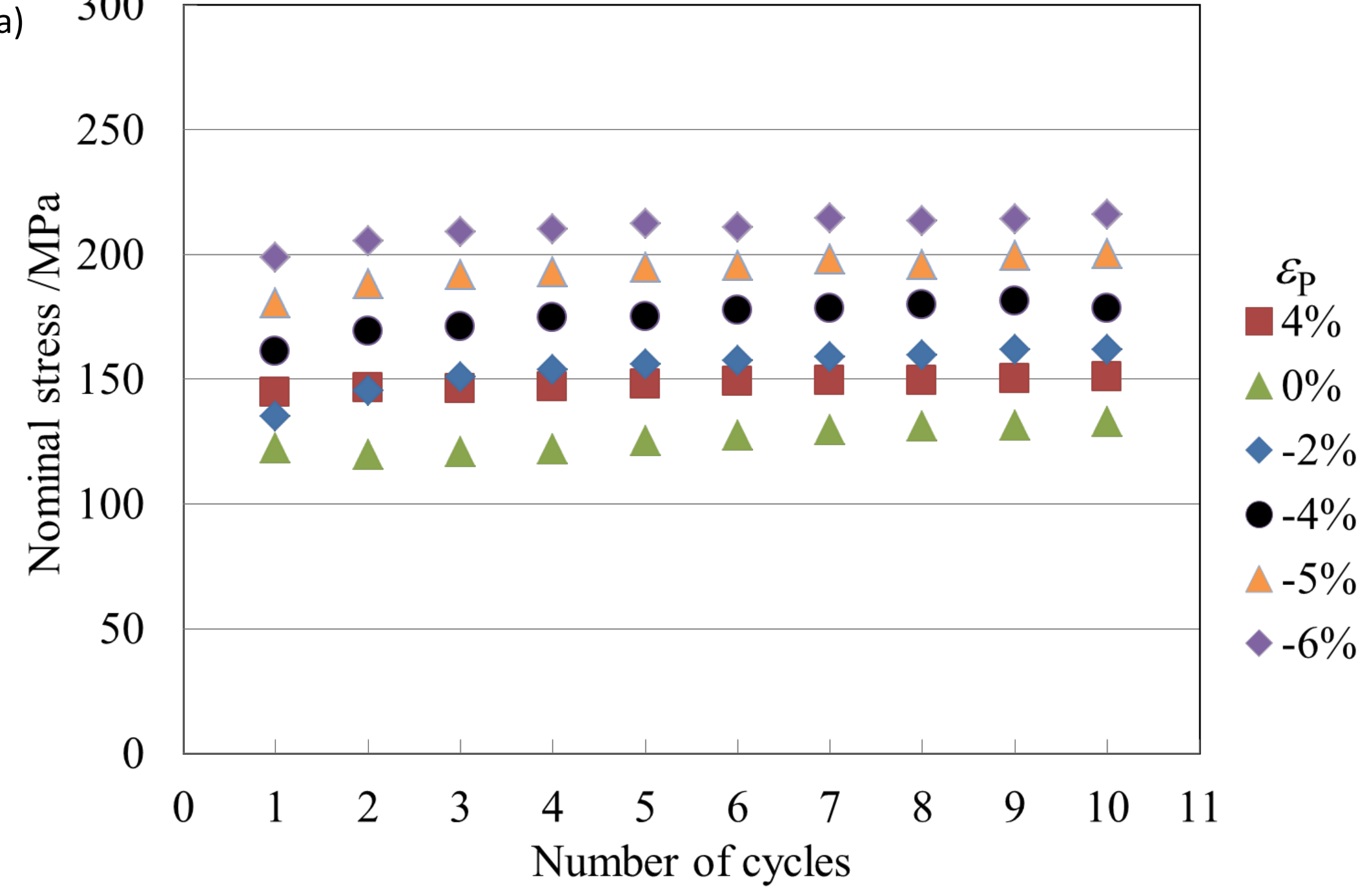

Fig. 9. Changes in stress at the end of tension and compression for the results with a strain amplitude of 2\%: (a) stress at the end of compression and (b) stress at the end of tension. 


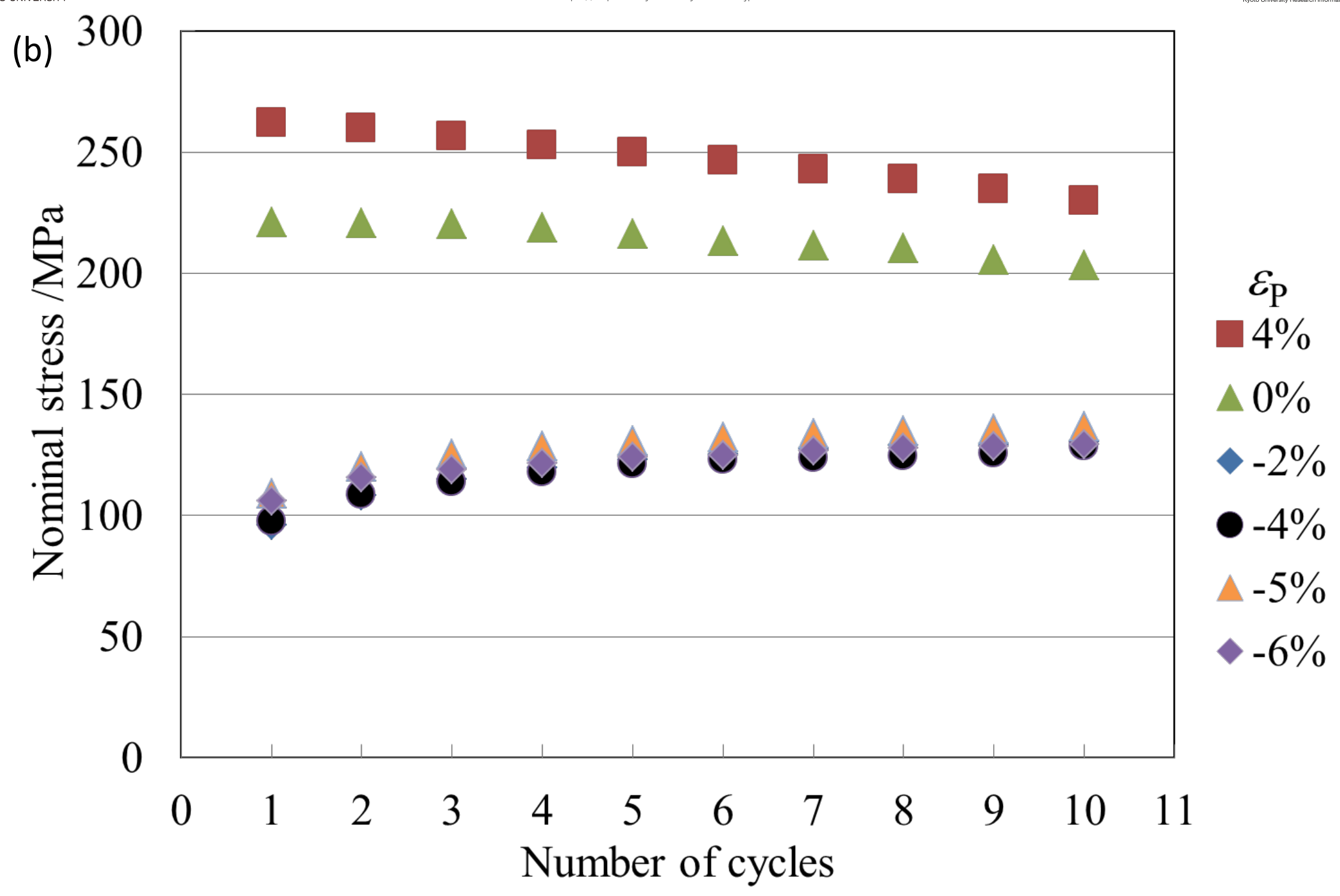

Fig. 9. Changes in stress at the end of tension and compression for the results with a strain amplitude of 2\%: (a) stress at the end of compression and (b) stress at the end of tension. 


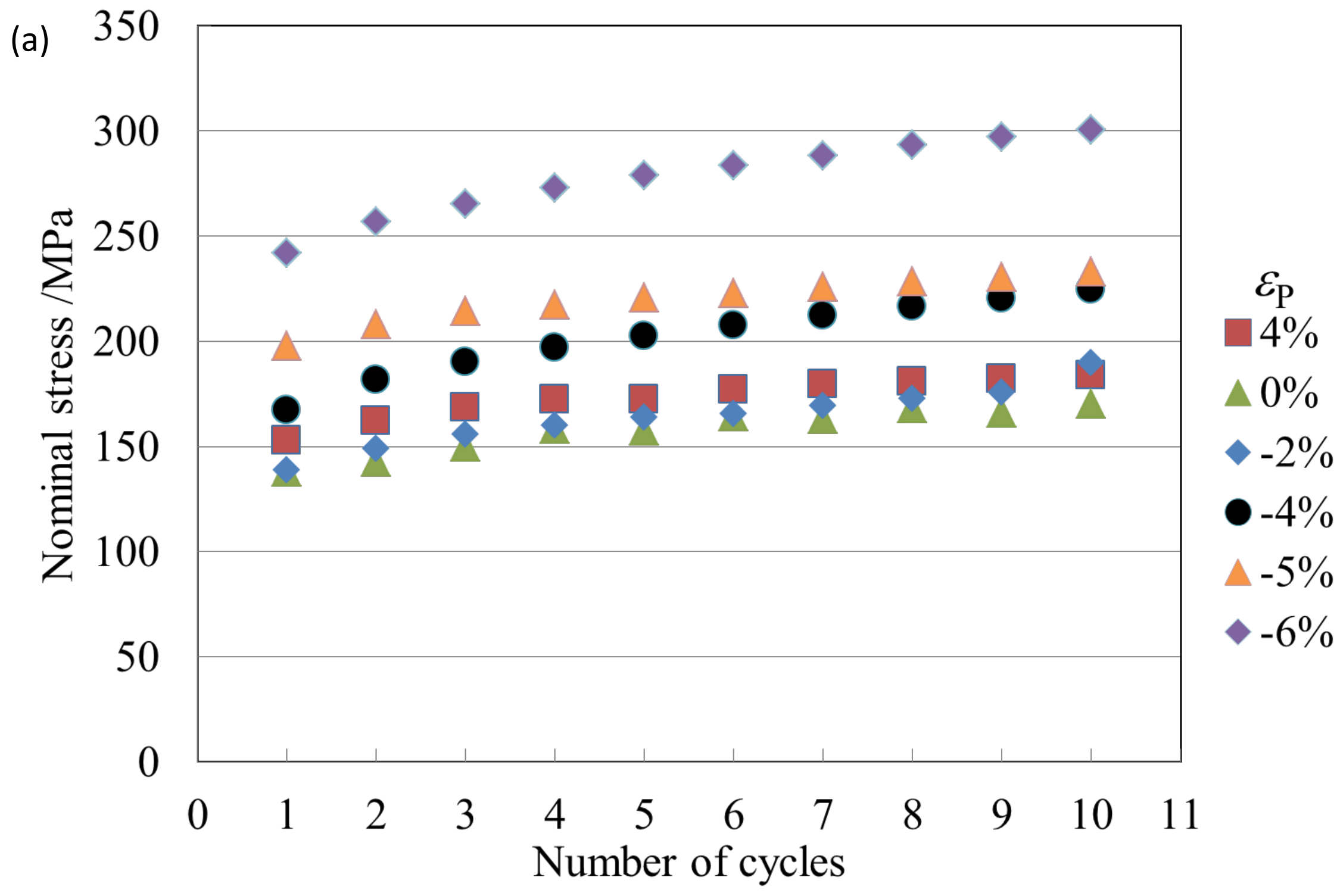

Fig. 10. Changes in stress at the end of tension and compression for the results with a strain amplitude of 4\%: (a) stress at the end of compression and (b) stress at the end of tension. 


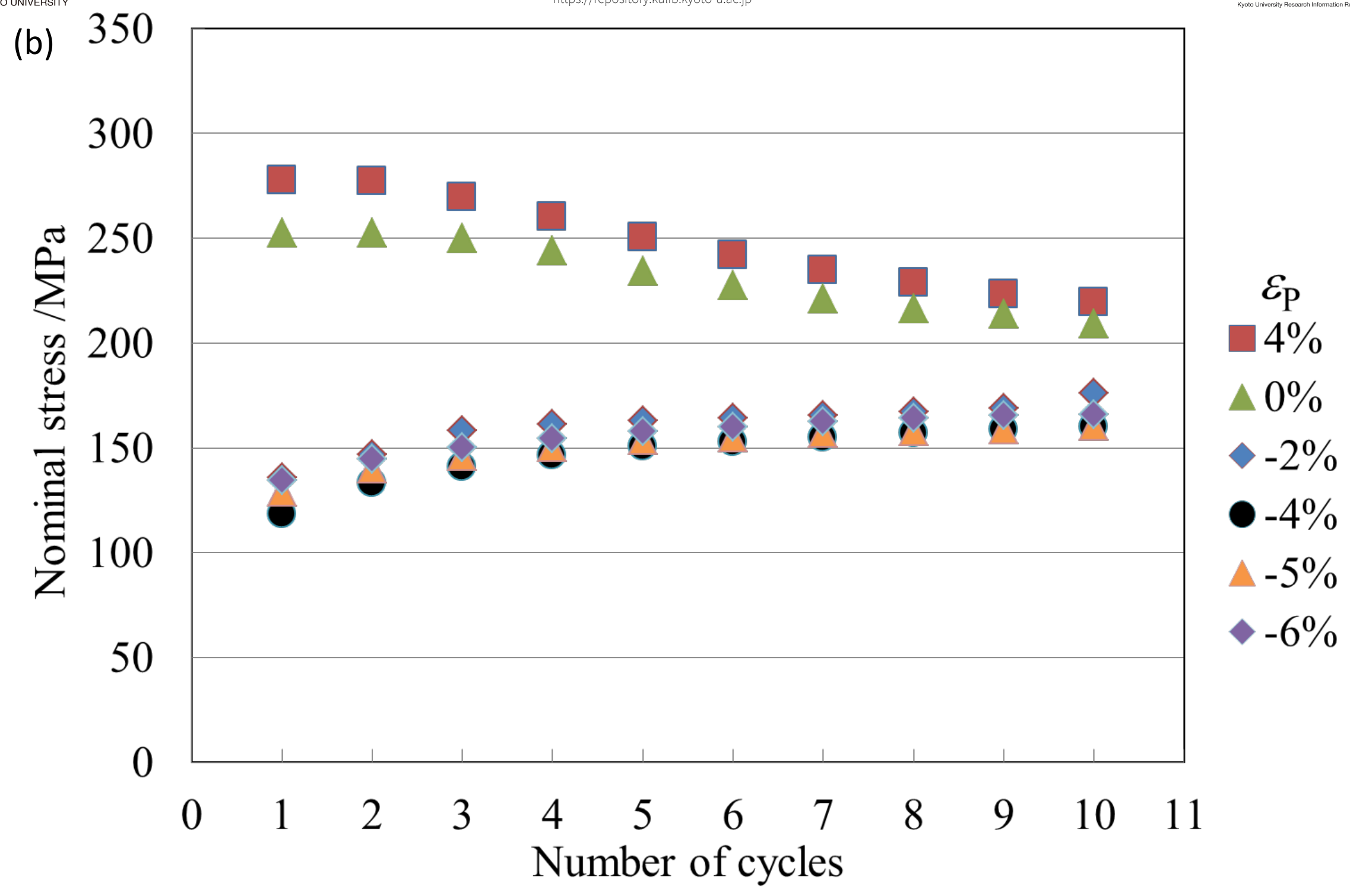

Fig. 10. Changes in stress at the end of tension and compression for the results with a strain amplitude of 4\%: (a) stress at the end of compression and (b) stress at the end of tension. 


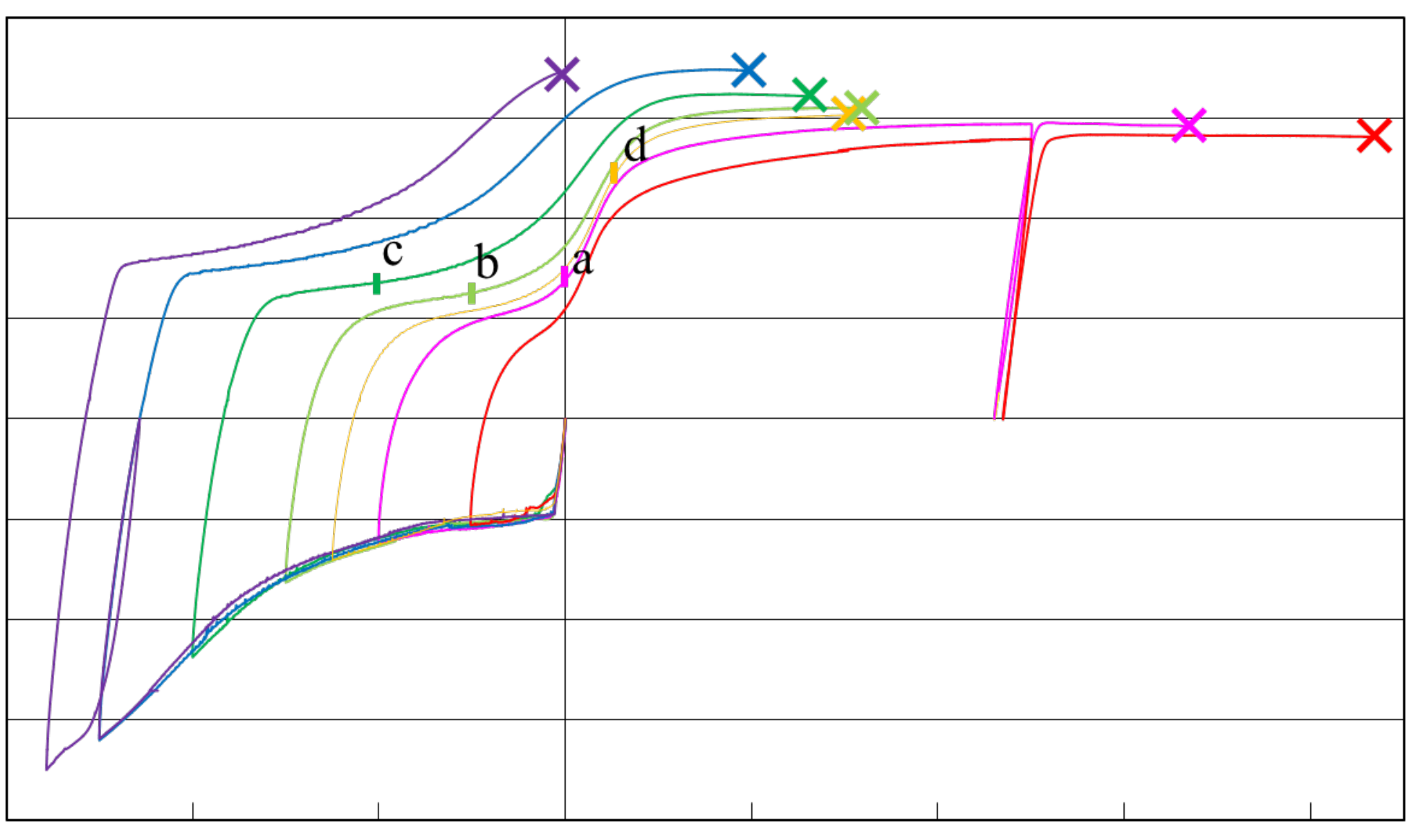

400

300

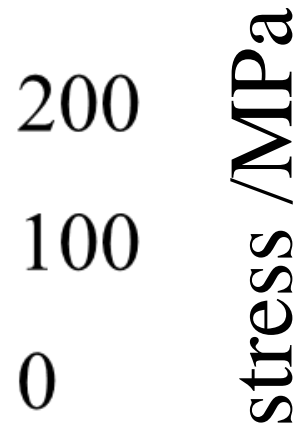

$-100$

$-200$

$-300$

$-400$

$\begin{array}{lll}-0.12 & -0.08 & -0.04\end{array}$

$\begin{array}{ll}0 & 0.04\end{array}$

0.08

0.12

0.16

Nominal strain

Fig. 11. Stress-strain curves obtained by reverse loading tests with various $\varepsilon_{\min }$ values. 


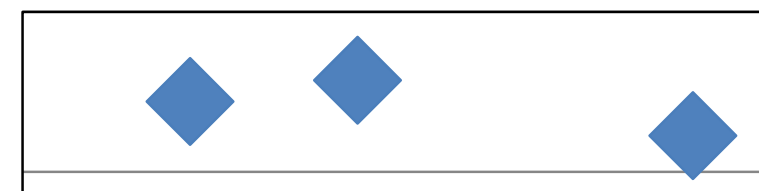

0.08

0.07

0.06

0.05

$0.04^{\omega}$

0.03

0.02

0.01

0

$\begin{array}{llll}-0.12 & -0.1 & -0.08 & -0.06 \\ & & & \varepsilon_{\text {min }}\end{array}$

Fig. 12. Relationship between $\varepsilon_{\min }$ and $\varepsilon_{\mathrm{T}}$. 


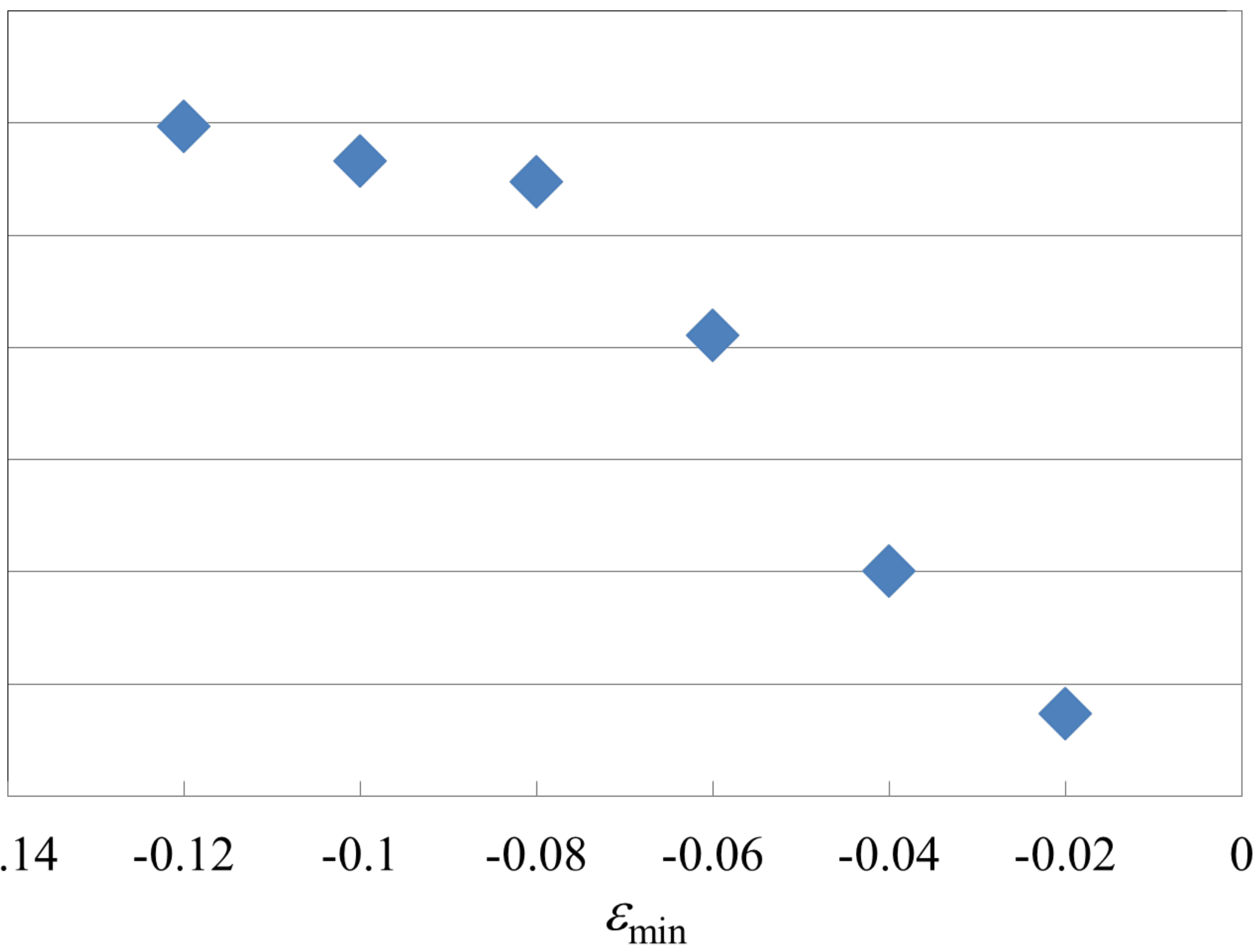

60

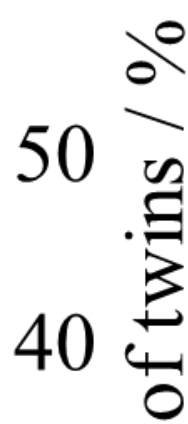

10

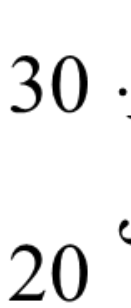

20

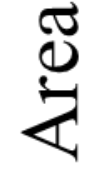

$\begin{array}{rrrrr}-0.14 & -0.12 & -0.1 & -0.08 & -0 \\ & & & \varepsilon_{\min }\end{array}$

0

Fig. 13. Relationship between $\varepsilon_{\min }$ and area fraction of twins. 


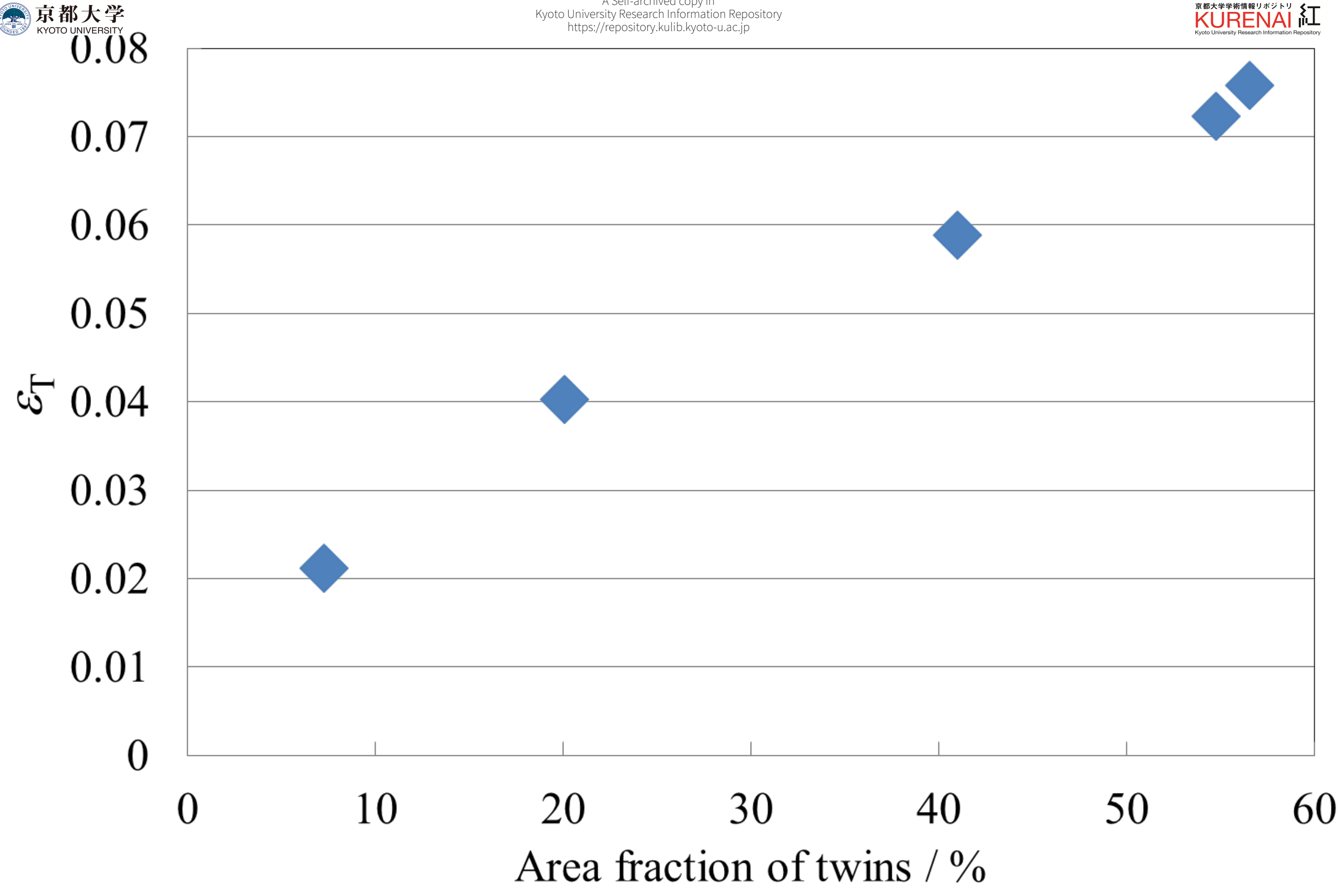

Fig. 14 Relationship between area fraction of twins and $\varepsilon_{\mathrm{T}}$. 


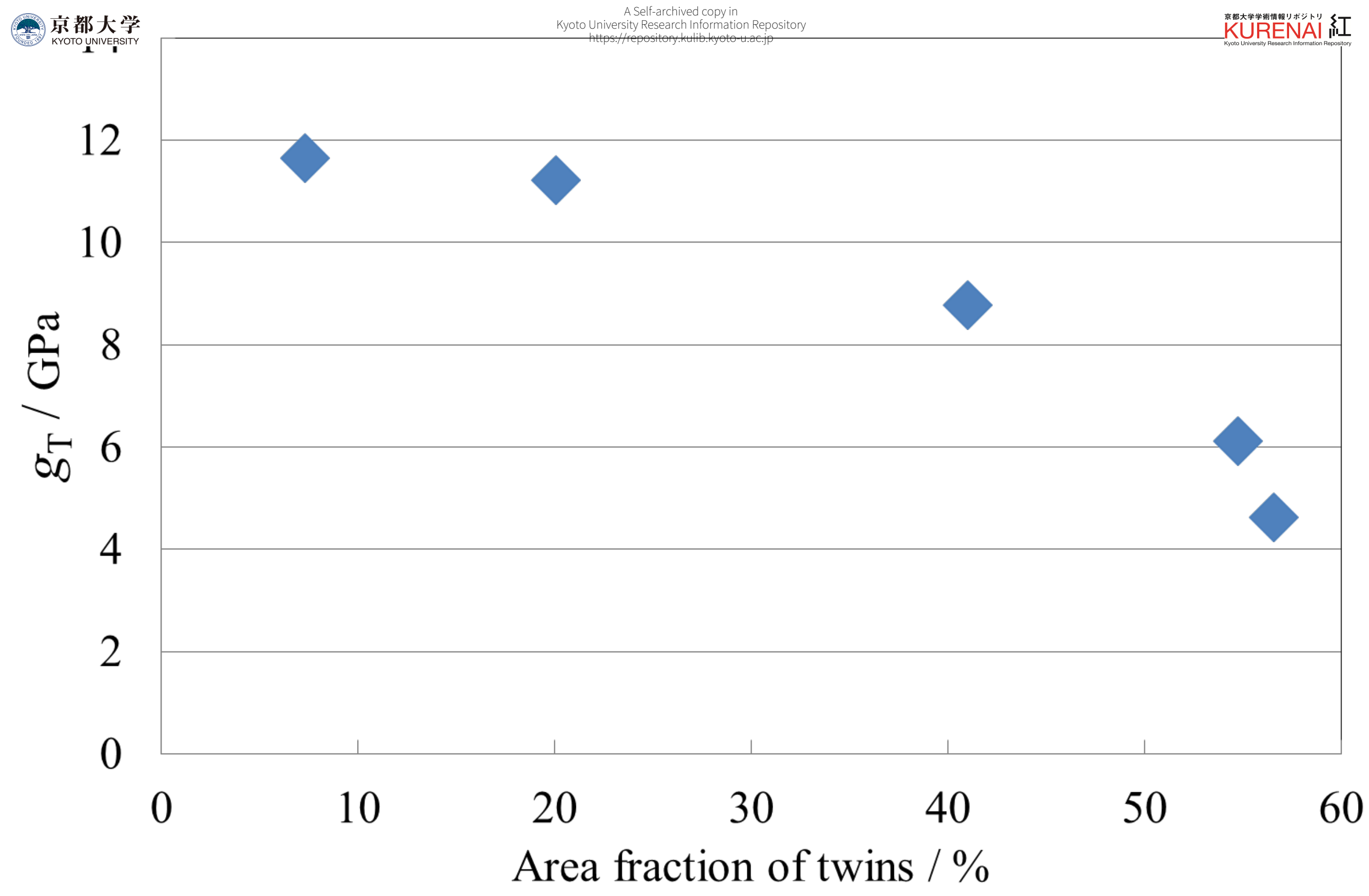

Fig. 15. Relationship between area fraction of twins and $g_{\mathrm{T}}$. 


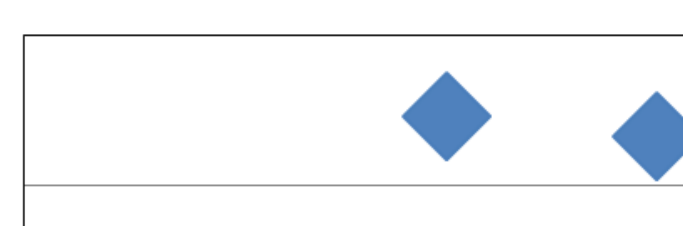

16

14

12

10

$8<$

6

4

2

0

$-0.1$

$-0.08$

$-0.06$

$-0.04$

$-0.02$

0

$\varepsilon_{\min }$

Fig. 16. Relationship between $\varepsilon_{\min }$ and $\rho_{\mathrm{T}}$. 


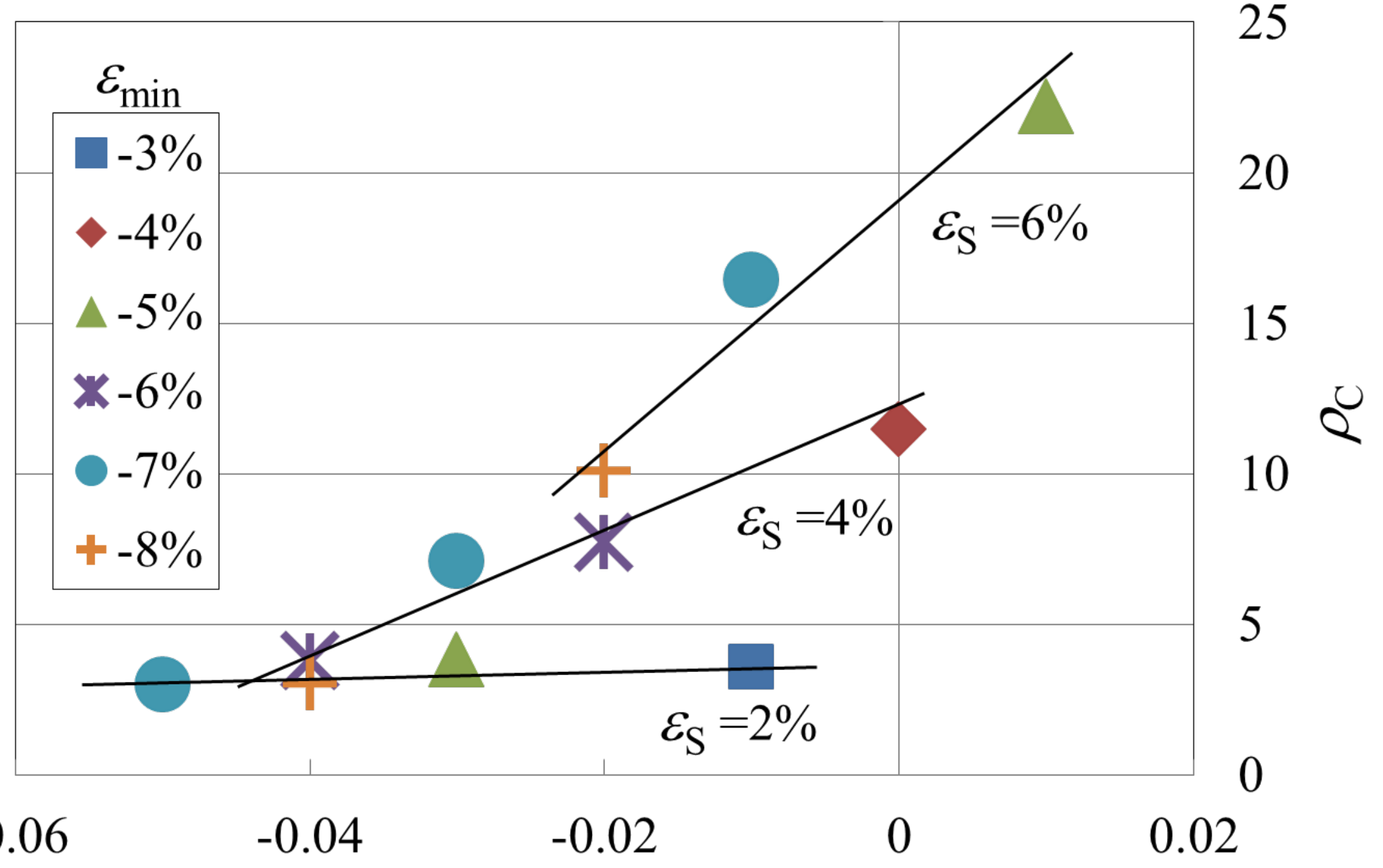

Strain at the beginning of compression

Fig. 17. Relationship between strain at the beginning of compression and $\rho_{\mathrm{C}}$. 